ARTÍCULO

\title{
PROYECTOS Y OBRAS PARA EL USO DE LOS TERRENOS DESECADOS DEL ANTIGUO LAGO DE TEXCOCO, 1912-1998*
}

\section{PROJECTS AND CONSTRUCTION WORK FOR USING THE DRIED LANDS OF THE FORMER LAKE TEXCOCO, 1912-1998}

\author{
Natalia Verónica Soto-Coloballes \\ Universidad Nacional Autónoma de México \\ Programa Universitario de Estudios sobre la Ciudad \\ Becaria posdoctoral \\ veronica.coloballes@gmail.com
}

\section{Resumen}

El presente trabajo examina las ideas acerca del posible uso de la tierra descubierta debido a la desecación del lago de Texcoco, producto del Desagüe del Valle de México. El texto explica la variedad de ideas propuestas por ingenieros y otros expertos, muchos de los cuales imaginaron un espacio de múltiples usos, con fines agrícolas, silvícolas, recreativos y ecológicos. La aportación de esta investigación consiste en mostrar cómo y por qué esos planes e ideas cambiaron a lo largo del siglo xx. Los resultados muestran que la transformación de su aspecto y naturaleza ha sido un anhelo constante, limitado por las especiales condiciones del subsuelo. Para la realización de esta investigación se consultó un gran número de fuentes escritas y se acudió al Archivo Histórico y Biblioteca Central del Agua y al Museo Archivo de la Fotografía.

Palabras clave: lago de Texcoco, uso de la tierra, bonificación, reforestación, tolvaneras, inundaciones.

\begin{abstract}
The present work examines the ideas related to the potential uses of the exposed Texcoco lake bed in the valley of Mexico. The text elaborates over the different projects proposed by engineers and other experts who imagined the desiccated area as a place for diverse uses, ranging from agriculture and forestry to natural reserve and even entertaining activities. The present investigation is aimed to explain why and how these ideas did change throughout the 20th century. The results show that the aim to reconvert the Texcoco bed has been a long-standing pretension being constrained by the geological conditions of its subsoil. The Archivo Histórico and the Biblioteca Central del Agua, as well as numerous written sources, are among the materials used for the purpose of the study.
\end{abstract}

Keywords: Texcoco lake, land use, reforestation, dust-storms, floods.

Información del artículo

Recibido: 9 de septiembre de 2019.

Aceptado: 3 de marzo de 2020.

DOI: 10.22201/iih.24485004e.2019.58.70695

* Programa de Becas Posdoctorales de la UnAM, Programa Universitario de Estudios sobre la Ciudad, unAm, asesorada por el doctor Javier Delgado Campos. Agradezco al Archivo Histórico y Biblioteca Central del Agua y al Organismo de Cuenca Aguas del Valle de México, ambos de la Comisión Nacional del Agua, así como al Museo Archivo Fotográfico de la Secretaría de Cultura de la Ciudad de México, el material proporcionado para esta investigación. 
El texto rastrea los proyectos concebidos para ejecutarse en el antiguo lecho del lago de Texcoco, a partir de su desecación y hasta finales de siglo. Su estructura es la siguiente: en primer lugar, se describen las características y los problemas del área de estudio. Luego, se exponen los proyectos de bonificación, reforestación, explotación de sales y regeneración del lago, con el fin de mostrar sus particularidades y contradicciones. Y finalmente, se presentan los proyectos, que teniendo como antecedentes los anteriores, desarrollaron grandes infraestructuras hidráulicas y delimitaron físicamente la zona. Esto último tiene el objetivo de proporcionar un panorama general pero completo de las obras que se han imaginado y que en ocasiones se han llevado a cabo a lo largo del siglo $\mathrm{xx}$, que aporten elementos de reflexión en las recientes disputas sobre el uso de estos terrenos y sus recursos naturales.

\section{"Duro pellejo de vaca que se llama llano"1}

El México contemporáneo se levantaba sobre un lago salado parcialmente desecado producto del Desagüe del Valle de México llevado a cabo durante el mandato del presidente Porfirio Díaz. ${ }^{2}$ Esta obra, que cumplió con el sueño colonial de una tierra seca, ${ }^{3}$ se concibió como un triunfo para la civili-

${ }^{1}$ Juan Rulfo, en su cuento "Nos han dado la tierra", hace referencia a las tierras sin valor para la agricultura que recibieron los campesinos como parte de la Reforma Agraria, y las que se parecen mucho a los terrenos del exlago de Texcoco. Para describirlas usa las siguientes expresiones: "duro pellejo de vaca que se llama llano", "costra de tepetate", "comal acalorado” y "blanco terregal endurecido”. Juan Rulfo, El llano en llamas, México, RM/Fundación Juan Rulfo, 2018, p. 7-12.

${ }^{2}$ Para profundizar en la historia del Desagüe del Valle de México véanse Luis González Obregón, Memoria histórica, técnica y administrativa de las obras del desagüe del valle de México, 1449-1900, México, Tip. de la Oficina Impresora de Estampillas, 1902; Manuel Perló, El paradigma porfiriano: historia del Desagüe del Valle de México, México, Universidad Nacional Autónoma de México, Programa Universitario de Estudios sobre la Ciudad, Instituto de Investigaciones Sociales/Miguel Ángel Porrúa, 1999, y Claudia Agostoni Urencio, Monuments of Progress. Modernization and Public Health in Mexico City, 1876-1910, Calgary/Boulder, University of Calgary Press/University Press of Colorado/Universidad Nacional Autónoma de México, Instituto de Investigaciones Históricas, 2003.

${ }^{3}$ La desecación de los lagos y la salida de las aguas de la ciudad, o el sueño colonial de una tierra seca, como Vera Candiani menciona, consistió en la realización de una serie de obras hidráulicas que, en conjunto, se conocen como Real Desagüe de Huehuetoca. Vera S. Candiani, Dreaming of Dry Land. Environmental Transformation in Colonial Mexico City, Stanford, Stanford University Press, 2014. 
zación y para la ciencia higiénica e hidráulica. El lago de Texcoco en sus épocas de mayor embalse cubría una superficie de $2000 \mathrm{~km}^{2}$ cuando se juntaba con los otros cinco lagos de la región: Zumpango, Xaltocan, San Cristóbal, Xochimilco y Chalco. ${ }^{4}$ En los albores del siglo Xx, este cuerpo de agua se redujo sustancialmente, pues apenas alcanzaba los $120 \mathrm{~km}^{2} .5$

Además, como estaba muy azolvado, era incapaz de contener las avenidas de los ríos que ahí desaguaban por ser la parte más baja de la cuenca, de modo que en época de lluvias éstos se desbordaban dando origen a las catastróficas inundaciones en la capital. En el estiaje este mismo lago tenía muy poca agua, mientras que el resto de las tierras eran una "llanura estéril, pantanosa por muchas partes y por otras con montículos de arena cargados de sales alcalinas". ${ }^{6}$ Esta situación, junto con los fuertes vientos del noreste, propiciaba la formación de tolvaneras: remolinos de polvo que caían sobre la ciudad, ensuciándola y afectando la salud humana, e incluso años más tarde paralizando la navegación área.

Las inundaciones y las tolvaneras encabezaban los grandes problemas sanitarios y más tarde ambientales adjudicados a las tierras descubiertas por el agua, consecuencia de las obras del desagüe. En los años veinte esta inmensa llanura se calculaba que medía entre 27000 y 29000 ha, de las cuales unas 12000 estaban ocupadas por el remanente del lago de Texcoco. Sobre esta área ingenieros, políticos y otros expertos empezaron a especular acerca de sus posibles usos con miras a resolver dichos inconvenientes, pero también para erigir la moderna y salubre capital a la cual aspiraba la elite gobernante.

La bonificación y la reforestación de las tierras desecadas

La creencia de que los terrenos desecados podían convertirse en campos cultivables empezó a circular con la desecación del lago de Chalco ocurrida

${ }^{4}$ Gerardo Cruickshank García, "Hacia una gestión integral de la cuenca del valle de México", en Gabriel Quadri de la Torre (comp.), Aguas residuales de la zona metropolitana de la ciudad de México, México, Friedrich Ebret/Departamento del Distrito Federal, 1989, p. 133.

${ }^{5}$ Gerardo Cruickshank García, Proyecto Lago de Texcoco. Rescate hidrológico, México, Sistemas Gráficos, 1998, p. 45.

${ }^{6}$ Mariano Barragán, "Proyecto de bonificación de las tierras del vaso del Lago de Texcoco, 1913”, en Comisión Nacional del Agua, Archivo Histórico y Biblioteca Central (en adelante Conagua-AHA), Fondo Consultivo Técnico, caja 200, exp. 1689, f. 4. 
a finales del siglo XIX, y llevada a cabo por Íñigo Noriega con el permiso de Porfirio Díaz, ${ }^{7}$ a fin de incorporar esas tierras a la agricultura comercial, con la que se esperaba obtener grandes rendimientos en detrimento de la economía lacustre, por cierto, fuera del control empresarial. ${ }^{8}$

Esto inspiró el "Proyecto de bonificación" del ingeniero Mariano Barragán, quien, con el apoyo del mandatario Francisco I. Madero (19111913), en julio de 1912 inició el drenado, lavado y fertilización de las tierras del vaso del lago de Texcoco a fin de hacer cesar su esterilidad debido a su alto contenido salino. La bonificación debía realizarse en 15000 ha; en el resto, proponía la construcción de caminos para garantizar la explotación agrícola, así como de un tanque regulador de 5488 ha, que funcionara como un depósito para recibir las crecientes de los ríos y luego conducirlas poco a poco por el Gran Canal, bajo la forma de gasto constante. ${ }^{9}$ La agricultura debía reemplazar las actividades locales basadas en la pesca y la cacería de animales acuáticos, además de terminar con el propio vaso salobre, y así defender a la ciudad de México de las inundaciones y de las tormentas de polvo que amenazaban con sepultar la capital. Por lo que mencionaba Barragán, existían "poderosas razones de higiene pública, a las que se juntaban las de mera conservación de la ciudad". ${ }^{10}$

La especulación de que las tierras desecadas podían hacerse fértiles quitándoles el tequesquite creció debido a que, "en regiones que pueden llamarse del mismo lago, como la hacienda de Aragón, parte de la de Tepexpan y otras, se ha[bía] logrado hacer cultivables sus tierras". ${ }^{11}$ Es el caso de las estaciones experimentales ubicadas en Netzahualcóyotl, en el kilómetro 5.5 del Gran Canal y en San Juan de Aragón. Y también el deseo de que la bonificación pudiera cambiar la tierra permitió a la agricultura sustituir el desierto salino y eliminar las tolvaneras. De lograrse la producción de maíz, trigo y frijol en esas tierras resultarían dos ventajas: la primera, que esa área

${ }^{7}$ Alejandro Tortolero Villaseñor, De la coa a la máquina de vapor, México, Siglo XXI, 1998, p. 265.

${ }^{8}$ Rodolfo Huerta González, “Agua, bosques y capitalismo: la región de Chalco, 18901940”, en Nicolás Hiernaux, Alicia Lindón Villoria y Jaime Noyola Rocha (coord.), La construcción social de un territorio emergente, México, El Colegio Mexiquense/Ayuntamiento Valle de Chalco Solidaridad, 2000, p. 76.

${ }^{9}$ Ibidem, f. 9.

${ }^{10}$ Ibidem, f. 10.

11 "Influencia que ha tenido en la climatología de la ciudad de México", Boletín del Servicio Meteorológico Mexicano, 1924, en Conagua-AHA, Fondo Consultivo Técnico, caja 200, exp. 1689 , f. 49. 
se convertiría en el nuevo granero de la ciudad de México, ${ }^{12}$ y la segunda, que se otorgaría un alto valor comercial a los terrenos rescatados.

Durante los años veinte la bonificación básicamente la realizaron pequeños propietarios que arrendaron y compraron lotes de hasta 20 ha para dedicarlos a la agricultura y, con ello, emprender un negocio propio. ${ }^{13}$ No obstante, en ningún caso éstos lograron modificar las condiciones de la tierra. El Estado en 1922 y luego en 1929 declaró de utilidad pública la bonificación de los terrenos desecados del lago. Esto convirtió dicha actividad en una tarea del Gobierno Federal. ${ }^{14}$

Así, en 1930, el entusiasmo por la explotación agrícola y los beneficios que traería para el futuro de la nación llevó a la administración del presidente Pascual Ortiz Rubio a aprobar el Parque Agrícola de la Ciudad de México. ${ }^{15}$ La pretensión era construir parcelas dedicadas a la agricultura, rodeadas de un sistema de acequias para comunicarse entre sí y con la antigua red de canales de la ciudad. También se planeaba la creación de un lago artificial y, en las orillas de éste, una pequeña urbe que llevaría el nombre de "la Ciudad del Lago", la cual constituiría el centro de las granjas agrícolas. ${ }^{16}$ Este proyecto nunca llegó a materializarse por falta de recursos;

12 "Desde los tiempos de la Colonia, Chalco había sido el granero por excelencia de la ciudad de México", debido a su clima templado y abundantes recursos hídricos. Huerta, "Agua, bosques y capitalismo...", p. 69.

${ }^{13}$ Diana Birrichaga Gardina y María del Carmen Salinas Sandoval, Cartografía hidráulica del Estado de México, México, Fondo Editorial Estado de México/El Colegio de Michoacán/ El Colegio Mexiquense, 2016, p. 295-296. Véanse los mapas en relación con el fraccionamiento y venta de los terrenos descubiertos por el lago de Texcoco.

${ }^{14}$ Margarita García Luna (Nezahualcóyotl, tierras que surgen de un desequilibrio ecológico, México, Gobierno del Estado de México, 1990, p. 39-48) ofrece un estudio monográfico de los decretos relativos a los terrenos desecados del lago de Texcoco desde 1912 y hasta 1940. Los siguientes tratan sobre el fraccionamiento, la explotación agrícola y la utilidad pública de la bonificación, respectivamente: "Acuerdo relativo al fraccionamiento de los terrenos del antiguo lago de Texcoco", Diario Oficial, 10 de noviembre de 1919; “Acuerdo dando a conocer varias disposiciones para la explotación agrícola de los terrenos procedentes de la desecación del lago de Texcoco", Diario Oficial, 17 de septiembre de 1921; “Acuerdo declarando de utilidad pública la bonificación de los terrenos desecados de la laguna de Texcoco”, Diario Oficial, 20 de septiembre de 1922, y "Acuerdo por el cual se declara de utilidad pública la bonificación y fertilización de los terrenos procedentes de la desecación del lago de Texcoco”, Diario Oficial, 11 de julio de 1929.

${ }^{15}$ Secretaría de Agricultura y Fomento, "Decreto por el cual se previene que deberán ejecutarse las obras para el drenaje, bonificación e irrigación de los terrenos desecados y desecables del lago de Texcoco”, Diario Oficial, v. LXVIII, n. 39, 19 de octubre de 1931, p. 2.

16 Véanse "Parque agrícola de la ciudad de México", El Nacional, 14 de octubre de 1931, y Ángel Peimbert, Augusto Petriccioli y Luis Mac Gregor, "Memoria descriptiva del proyecto 
no obstante, reitera el anhelo por cambiar la naturaleza salobre de la tierra y utilizarla para la agricultura de manera parecida a como se hacía en el lago de Xochimilco.

La viabilidad del proyecto de bonificación fue cuestionada por Miguel Ángel de Quevedo, Pablo Bistráin y Gonzalo Blanco, quienes observaban el alto costo de la bonificación y las grandes cantidades de agua dulce utilizadas para el lavado de las tierras. Además, señalaban el poco éxito obtenido en comparación con la larga duración de los trabajos. En esto coincidían los ribereños del lago, quienes expresaban que se trataba de un absurdo, como "sembrar sobre un comal". ${ }^{17}$ Hasta 1949 se había logrado bonificar la zona sudoeste del lago, de escasa concentración de sales, y se había gastado la cuantiosa suma de 32 millones de pesos. ${ }^{18}$ De este modo en todos esos años únicamente 2600 ha habían podido ser bonificadas; el resto, aproximadamente unas 15000 ha, resultaba inviable por el alto contenido salobre.

A la par de los trabajos de bonificación, se desarrolló la idea de la silvicultura promovida ampliamente por la Sociedad Forestal Mexicana y su revista México Forestal. ${ }^{19}$ Detrás de esta propuesta estaba Miguel Ángel de Quevedo, para quien la forestación de los terrenos desecados con bosques y prados resistentes a la sal era la mejor vía económica y técnicamente posible para restablecer la salubridad, regularizar el clima, evitar la erosión, y también contribuir a la belleza del paisaje, ${ }^{20}$ que incluso podía ser aprovechada para la cría de ganado lanar. ${ }^{21}$ En 1907, Quevedo había visitado los Bajos Alpes franceses - las Landas de Gascuña- y las colonias francesas

del Parque Agrícola de la ciudad de México", Planificación, v. 2, n. 5, octubre-noviembre de 1934 , p. 39.

17 "Si no se buscan otros medios", El Nacional, 9 de mayo de 1933.

${ }^{18}$ Gonzalo Blanco, Las tolvaneras o tormentas de polvo en el valle de México, en Conagua-AHA, Fondo Aprovechamientos Superficiales, caja 2766, 1949, exp. 38699, f. 36.

${ }^{19}$ La Sociedad Forestal Mexicana se constituyó en noviembre de 1921 "por un grupo de personas convencidas del importante papel que desempeña la vegetación forestal y muy principalmente el bosque o foresta arbolada, en el equilibrio climatérico, en la protección del suelo y de las aguas y en la economía general y bienestar público; convencidas aún más de estos benéficos efectos por la manifiesta acción perjudicial que su ruina está acarreando en el territorio mexicano”, Gilberto Serrato, “Aniversario de los primeros Xxv años de vida de la revista México Forestal y síntesis de la historia del servicio Forestal Mexicano”, México Forestal, v. 26, n. 1-4, 1948, p. 3.

${ }^{20}$ Miguel Ángel de Quevedo, "Las polvaredas de los terrenos tequezquitosos del antiguo lago de Texcoco y los procedimientos de enyerbe para remediarlas", México Forestal v. 5, n. 5-6, 1927, p. 51.

${ }^{21}$ De Quevedo, “Las polvaredas de los terrenos tequezquitosos...”, p. 47. 
del norte de África - Argelia y Túnez- para observar cómo se fijaban médanos en las tierras arenosas y así evitar la sepultura de poblados y campos de cultivo. De este viaje no solamente trajo la idea de la reforestación y cubierta vegetal para el exvaso del lago de Texcoco, sino también una buena cantidad de semillas de acacias mimosas y eucaliptos, yerbales y arbustos, donadas según comenta, por el director forestal de Argelia, Monsieur Boutilly, ${ }^{22}$ con el fin de sembrarlas en las tierras salinas; su idea era que cuando estos árboles y plantas crecieran pudieran servir de filtros para retener el polvo y también para absorber el anhídrido carbónico de la atmósfera. De este modo el vaso del lago de Texcoco se transformaría en un lugar sano y limpio, mejorando la salud humana y la apariencia de la capital del país, la que imaginaba cercana a la estética de las ciudades europeas.

Pero no todos coincidían con esta propuesta, el agrónomo Gonzalo Blanco la criticó; mencionaba que la medida daría resultados satisfactorios, dentro de cuarenta o cincuenta años, cuando los árboles hubieran formado un espeso follaje y alcanzaran alturas importantes para construir una barrera efectiva contra los vientos del noreste. Además de que se trataba de una "acción aislada de un solo recurso (árboles) que no consideraba el complejo y delicado equilibrio de los factores que integraban la ecología del lugar", ${ }^{23}$ lo que la mera plantación de éstos no tomaba en cuenta es la estrecha interacción que, según consideraba, existía entre todos los recursos bióticos del valle de México.

La bonificación y reforestación de los terrenos desecados se ajustó a la propuesta política del presidente Lázaro Cárdenas: mientras la primera le permitía satisfacer las demandas ejidales relacionadas con la redistribución de la tierra, la segunda prometía terminar con las tolvaneras. Por eso, en 1938, se publicó un acuerdo en el Diario Oficial que daba preferencia a los campesinos y ejidatarios de los pueblos circunvecinos, en la ejecución de las obras de bonificación del lago de Texcoco. ${ }^{24}$ Para atender la reforestación, entre muchas otras funciones, Miguel Ángel de Quevedo fue invitado para

${ }^{22}$ Miguel Ángel de Quevedo, "Las resoluciones de los Congresos Internacionales de Higiene de 1900 en París y de 1907 en Berlín”, México Forestal, v. 18, n. 3-4, 1940, p. 22.

${ }^{23}$ Blanco Gonzalo, Las tolvaneras o tormentas de polvo en el valle de México, Conagua-AHA, Fondo Aprovechamientos Superficiales, caja 2766, exp. 38699, 1949, f. 38.

${ }^{24}$ Departamento Agrario, "Acuerdo que previene se dé preferencia a los campesinos y ejidatarios de los pueblos circunvecinos, en la ejecución de las obras de bonificación del lago de Texcoco", Diario Oficial de la Federación, v. cx, n. 31, 7 de octubre de 1938, p. 6. 
dirigir el Departamento Forestal. Pero, debido a las contradicciones entre la justicia agraria y la silvicultura, se reavivaron los conflictos por la propiedad y el uso de la tierra en este espacio. Éstos se cristalizaron, dice el historiador Matthew Vitz, en una competencia entre los derechos locales por la tierra y los recursos, y el estricto programa de conservación de Quevedo. ${ }^{25}$ Esto llevó a que "los residentes del lago se encontraron entre las promesas a medias de la reforma agraria y el malestar del proyecto de bonificación”. ${ }^{26}$

La explotación de las sales

En el sexenio de Ávila Camacho, los intentos para reducir la salinidad de las tierras convergieron con el negocio de explotar las sales disueltas en el borde norte del lecho del lago. Se trataba de una actividad rudimentaria ejercida por los locales de la zona, la que fue industrializada con la creación de la empresa paraestatal Sosa Texcoco, y que los excluyó de las cuantiosas ganancias. ${ }^{27}$ En poco tiempo se convirtió en la industria de álcali más importante de América Latina, pues en 1948 producía 100 toneladas diarias, mediante el evaporador solar conocido como "El Caracol". ${ }^{28}$ El evaporador tenía una superficie aproximada de 850 ha, que concentraba las aguas saladas provenientes del lavado de tierras. Las instalaciones también contaban con una refinería o planta piloto para producir carbonato de sodio y sosa cáustica. ${ }^{29}$

Este jugoso negocio inspiró al ingeniero Miguel Brambila, subdirector de Aprovechamientos Hidráulicos de la Secretaría de Recursos Hidráulicos, quien en ese mismo año presentó un anteproyecto de obras hidráulicas dedicadas a la explotación de sales alcalinas en prácticamente toda la zona

${ }^{25}$ Matthew Vitz, A City on a Lake. Urban Political Ecology and the Growth of Mexico City, Durham (North Carolina), Duke University Press, 2018, p. 125.

${ }^{26}$ Vitz, A City on a Lake..., p. 138.

${ }^{27}$ Gabriel Espinosa Pineda, El embrujo del lago. El sistema lacustre de la cuenca de México en la cosmovisión mexica, México, Universidad Nacional Autónoma de México, Instituto de Investigaciones Históricas, Instituto de Investigaciones Antropológicas, 1996. Documenta los conocimientos y prácticas locales para llevar a cabo la caza, la pesca y la recolección de la fauna, "de las criaturas del lago y sus alrededores”, así como su importancia para la economía y la subsistencia de los pueblos.

${ }^{28}$ Benito Bucay, “Apuntes de historia de la química industrial en México”, Revista de la Sociedad Química de México, v. 45, n. 3, 2001, p. 138.

${ }^{29}$ Secretaría de Hacienda y Crédito Público, Proyecto Texcoco. Memoria de los trabajos realizados y conclusiones, México, Secretaría de Hacienda y Crédito Público, 1969, p. 15. 
del lago, con el que pretendía generar 40 millones de pesos anuales para el Gobierno Federal. Para este fin destinaba 3000 y 6000 ha para la construcción de las cajas de agua poniente y sur, respectivamente, de donde extraería por bombeo el agua salobre del manto freático. Y para evaporarlas y concentrarlas reservaba 11700 ha. ${ }^{30}$

El proyecto nunca se ejecutó por su alto costo, estimado en 16300000 pesos, y porque su ejecución suponía la extracción de grandes cantidades de agua, lo que tenía como consecuencia el hundimiento de grandes zonas de la ciudad. De hecho, su idea era aprovechar hasta la última gota del líquido freático salino, a manera de "reconquistar" los terrenos desecados. Brambila no se preocupaba por el agotamiento de este recurso ni por su impacto en el ambiente, incluso lo veía como algo positivo ya que la explotación de las sales cumplía también con el deseo de modificar la naturaleza de la tierra.

La regeneración del lago y el desequilibrio ecológico

En un principio, la regeneración del lago de Texcoco fue la idea más criticada porque parecía desconocer el beneficio de la obra del desagüe y olvidar la batalla de siglos contra las inundaciones, y los padecimientos derivados de las aguas estancadas. ${ }^{31}$ No obstante, a mediados de siglo, eso cambió; la devolución del agua al antiguo lago se evaluaba con seriedad, lo malo no eran los lagos, sino el desequilibrio ecológico del valle de México. Éste se explicaba por la continua extracción de agua de los mantos acuíferos, debido a la demanda del recurso por parte de una población cada vez más grande. Mientras que en 1900 había poco más de medio millón de

${ }^{30}$ Miguel Brambila, Lineamientos generales para el proyecto de obras, Conagua-AHA, Fondo Consultivo Técnico, caja 177, exp. 1424, 1947, f. 6.

${ }^{31}$ El lago de Texcoco durante el siglo xix encarnó el origen de la insalubridad de la ciudad; se le consideró fuente de emanaciones pútridas y causa de alta mortalidad. La historiadora Laura Cházaro explica que su desecación era necesaria tanto para evitar los derrames de inmundos contenedores de los productos y desechos de la ciudad como para romper con el pasado indígena y la infección que los indios habían dejado debido a las inhumaciones de sus muertos. Laura Cházaro García, "El lago de Texcoco y la ciudad de México: entre las diferencias políticas y la higiénica igualdad”, en Eulalia Ribera Carbó, Héctor Mendoza Vargas y Martín Pere Sunyer (coords.), La integración del territorio en una idea de Estado. México y Brasil, 1821-1946, México, Universidad Nacional Autónoma de México, Instituto de Geografía/Instituto de Investigaciones Dr. José Luis Mora, 2007, p. 423-441. 
habitantes, cinco décadas después había tres millones de habitantes que requerían 90001 por segundo de agua, ${ }^{32}$ lo que ocasionaba una sobreexplotación de los acuíferos. Esta situación tenía como consecuencia la consolidación de la arcilla del subsuelo, es decir, los hundimientos y agrietamientos del valle de México, debido a que el líquido extraído no se podía reponer en gran parte porque el lago estaba seco. ${ }^{33}$ Así, en 1950, el fondo del lago dejaba de ser el punto más bajo del valle; estaba alrededor de tres metros más alto que la parte más hundida de la ciudad. ${ }^{34}$ Esta vez, las inundaciones no se debían al desbordamiento de los lagos y ríos, sino a que la ciudad se encontraba por arriba del Gran Canal. Como mencionaba el ingeniero Orive Alba: "La ciudad de México se inundaba por falta de agua". ${ }^{35}$

El hundimiento y el sobreaprovechamiento de los mantos acuíferos se sumaban a los problemas ambientales, de modo que el desequilibrio ecológico estaba íntimamente conectado con la desecación de los lagos; esto llevó a pensar a los ingenieros y a otros expertos que su restauración se encontraba, en su rescate hidrológico, es decir, en la regeneración de los lagos, ${ }^{36}$ y posteriormente en la creación de cuerpos de agua artificiales.

En 1949, en el marco del Primer Congreso Internacional de Ingeniería Civil en México, Fernando Vizcayno, gerente general de las Obras del Valle de México, y el ingeniero Pablo Bistráin elaboraron un estudio que se ofrecía como una alternativa al presentado por Miguel Brambila, con el objetivo de eliminar las tolvaneras de la ciudad de México, así como para mejorar el clima y el suelo de la zona. Dicha propuesta resultaba más económica que la de Brambila; requería una inversión de ocho millones de pesos, y además daba seguimiento a los trabajos efectuados anteriormente relacionados con la industrialización de las sales y con la bonificación en la zona

${ }^{32}$ Adolfo Orive Alba, "Los problemas del valle de México", Ingeniería Hidráulica en México, v. 6, n. 2, 1952, p. 7.

${ }^{33}$ Las causas últimas del hundimiento fueron explicadas en 1947 por Nabor Carrillo mediante la teoría clásica de la consolidación, la que se explicaba por las características excepcionales del subsuelo, el cual estaba formado por un tipo de arcilla, relativamente blanda y de alta compresibilidad, que contenía agua en proporción a sólidos de 7 a 1, por lo que al extraer el líquido se daba lugar a su asentamiento. sнcP, Proyecto Texcoco. Memoria..., p. x.

${ }^{34}$ Orive, “Los problemas del valle de México...”, p. 8.

${ }^{35}$ Agustín de Neymet, "Inundaciones”, Ingeniería Hidráulica en México, v. 6, n. 2, 1952 , p. 2.

${ }^{36}$ Esta no era una idea nueva; a finales del siglo xıx, Manuel Balbontín ya había sugerido el desazolve y la profundización del lago mediante el empleo de dragas. Manuel Balbontín, “El lago de Texcoco”, Boletín de la Sociedad Mexicana de Geografía y Estadística, 1873, p. 375. 
sudoeste. Ésta consistía en mantener sumergidas las áreas del lago, correspondientes a $122 \mathrm{~km}^{2}$, y húmedos los terrenos colindantes durante el periodo de estiaje, cuando ocurrían las tormentas de polvo. ${ }^{37}$ La cota de sumersión se calculaba en $6.4 \mathrm{~m}$ y la capacidad de almacenamiento en 37 millones de metros cúbicos. El llenado del lago dependía de los recursos hidráulicos superficiales, es decir, de los ríos del oriente, incluido el de Churubusco, de las presas de Guadalupe, de río Cuautitlán y de Castro, así como de las aportaciones de agua realizadas por bombeo. ${ }^{38}$

A la par de este proyecto, Gonzalo Blanco Macías, durante el Primer Congreso Interamericano de Campesinos y Agrónomos, sugería la reposición del agua a todos los vasos de los ya extintos lagos del valle de México con el fin de revertir el proceso de desecación. Esto, propuso, se haría mediante la utilización de maquinaria y equipo pesado para desazolvarlos y "profundizarlos hasta unos 5 o 6 metros bajo el nivel actual de los sedimentos, y llenándolos nuevamente con agua limpia y cristalina". ${ }^{39}$ Esta agua, a su vez, sería procedente de la purificación de las aguas negras de la ciudad de México en plantas de tratamiento, como se hacía en algunas ciudades de Europa y Estados Unidos. ${ }^{40}$ Para complementar su plan sugería la plantación de árboles y la siembra tanto de pastos como de leguminosas perennes para ofrecer en unos cuantos meses una protección efectiva al suelo. ${ }^{41}$ Para este agrónomo, el desequilibrio ecológico del valle de México no eran problemas de ingeniería, sino de ecología y de conservación de suelos y aguas; por eso su plan contemplaba la reposición del agua a todos los vasos de los ya extintos lagos del valle de México, con el fin de elevar el nivel de las aguas freáticas, enriquecer los mantos artesianos, aumentar el caudal de los manantiales, reponer la fauna acuática, aumentar la humedad atmosférica, estabilizar el subsuelo deteniendo su hundimiento y terminar con las tolvaneras.

Estas propuestas influyeron en Eduardo Chávez, secretario de Recursos Hidráulicos (1952-1958), quien en abril de 1953 realizó un vuelo de reconocimiento en la zona para mostrar a un grupo de periodistas la devolución de las aguas al desecado lago. Las obras de rehidratación, como se las nom-

${ }^{37}$ Fernando Vizcayno y Pablo Bistráin, "Diversos aspectos del valle de México”, Conagua-AHA, Fondo Aprovechamientos Superficiales, caja 2766, exp. 38699, 1949, f. 111.

${ }^{38}$ Ibidem, f. 112.

${ }^{39}$ Blanco Gonzalo, Las tolvaneras o tormentas de polvo en el valle de México, Conagua-AHA, Fondo Aprovechamientos Superficiales, caja 2766, exp. 38699, 1949, f. 43.

${ }^{40}$ Ibidem, f. 43.

${ }^{41}$ Ibidem, f. 38. 
bró, consistían en mantener una lámina de agua equivalente a la que tenía a principios de siglo, procedente de trece ríos y del agua tratada del Gran Canal del Desagüe. En total 11000 ha, que se sumaban a las 5000 ha alojadas en la parte más profunda de la cuenca, a las que, se afirmaba, nunca les faltó el líquido. ${ }^{42}$ De este modo, se anunciaba que "16 mil hectáreas [se arrebataban] a las tolvaneras". ${ }^{43}$

Los miembros de la Comisión Técnica Intersecretarial para las Obras del Valle de México, creada en 1942, criticaron el llenado de los lagos; entre sus principales objeciones mencionaban, por un lado, las relacionadas con el desbordamiento de las aguas sobre las colonias vecinas y sobre la propia ciudad en época de lluvias, dado el azolvamiento de los terrenos y el hundimiento de la ciudad, y, por otro, la evaporación del agua durante el estiaje. Además de que decían, estas aguas no podían ser desalojadas a través del Gran Canal por los daños que el alto contenido salobre podía causar a los cultivos de riego del valle del Mezquital, que era el destino final de las aguas. ${ }^{44}$

Unos años antes de que se llevara a cabo la rehidratación de la zona y se pensara en formar cuerpos de agua artificiales tanto Adolfo Orive Alba, secretario de Recursos Hidráulicos (1947-1952), como Miguel Ángel de Quevedo rechazaban completamente la posibilidad de excavar un vaso e inundarlo de agua para volver a tener el perdido lago de Texcoco. El primero mencionaba que se trataba de una obra absurda puesto que, para profundizar $5 \mathrm{~m}$ una superficie de 280 millones de metros cuadrados, "habría que sacar un volumen de 1400 millones de metros cúbicos, equivalente a mover tierras y terracerías [algo similar a] 100 veces una presa como la del Papaloapan, la más grande de América Latina". ${ }^{5}$

El segundo aseguraba que dicha obra estaba fundada en un "desconocimiento completo de la cuestión, la remoción de tierras para obtener un lago de 10 mil hectáreas de superficie y 2 metros de profundidad, capaz de mantener las aguas torrenciales en los cinco meses de estiaje, exigiría una remoción colosal de tierra, o sea de 200 millones de metros cúbicos, muy superior a la remoción de tierras del Gran Tajo de Nochistongo y de todas

42 Adrián García, "México comienza a recuperar sus viejos lagos”, El Universal, 12 de abril de 1953, Conagua-AHA, Fondo Consultivo Técnico, caja 173, exp. 1377, f. 113.

${ }^{43}$ Ibidem, f. 113.

${ }^{44}$ Ibidem, f. 113.

45 Orive, "Los problemas del valle de México...", p. 8. 
nuestras pirámides”. ${ }^{46}$ Además, según sus cálculos, no había aguas en cantidad suficiente y permanente, ni juntando las aguas de todos los ríos que concurrían en el lago, ni con las aguas de desecho del Canal Nacional y del Antiguo Canal de San Lázaro. ${ }^{47}$

Creación de cuerpos de agua

La idea de la rehidratación del lago se transformó en la de cuerpos de agua profundos y de poca superficie expuesta; es decir, el lago dejaba de ser un cuerpo natural de agua salobre para convertirse en uno artificial producto de las obras hidráulicas. Este cambio se debió a los trabajos realizados por la Comisión Hidrológica de la Cuenca del Valle de México, pero sobre todo a los estudios y experimentos llevados a cabo por el Proyecto Texcoco. En la década de los años sesenta la desecación de los lagos se consideró un "error" y para enmendarlo estaban los ingenieros. Las obras hidráulicas constituyeron el mejor medio para resolver los problemas ecológicos de los terrenos desecados, paradójicamente, para tratar de solucionar los problemas derivados de otros trabajos e intervenciones. ${ }^{48}$

En 1963, la Comisión Hidrológica de la Cuenca del Valle de México, creada por acuerdo presidencial para estudiar y determinar los trabajos relativos al aprovechamiento de los recursos hidráulicos y sus usos, suscribía la idea de reducir por etapas el lago de Texcoco, hasta alcanzar 2000 ha y 25.5 millones de metros cúbicos de almacenamiento. ${ }^{49}$ Mientras que, en 1969, las conclusiones del Proyecto Texcoco señalaban el método de bombeo en pozos someros para la construcción de cuatro pequeños lagos con capacidad de 150 millones de metros cúbicos en una superficie de 2700 ha.

${ }^{46}$ Miguel Ángel de Quevedo, "Los desastres de la deforestación en el valle y ciudad de México”, México Forestal, v. 7, n. 6, 1929, p. 118.

${ }^{47}$ De Quevedo, “Los desastres de la deforestación...”, p. 117.

${ }^{48}$ Perló, El paradigma porfiriano...

${ }^{49}$ Comisión Hidrológica de la Cuenca del Valle de México, Lineamientos generales del Plan Hidráulico para la Cuenca del Valle de México (alternativa 1960-1990), México, Secretaría de Recursos Hidráulicos, 1966, p. 179-180 (en adelante CHCVM). Cabe mencionar que, el 20 de abril de 1963, se fundó oficialmente el municipio 120 del Estado de México, Ciudad Nezahualcóyotl. Jaime Linares Zarco, Ciudad Nezahualcóyotl, de la pobreza a la globalización económica y la saturación urbana, México, Universidad Nacional Autónoma de México, Facultad de Estudios Superiores Aragón, 2013, p. 75. 
En julio de 1965, Nabor Carrillo propuso al Gobierno Federal la ejecución del Proyecto Texcoco con el fin de explorar los diversos procedimientos técnicos orientados a "exprimir la esponja del subsuelo"; ${ }^{50}$ investigar la composición química de las aguas subterráneas, y llevar a cabo las pruebas relacionadas con la elección del mejor método de construcción para la creación de uno o varios vasos de almacenamiento y de regularización de las aguas en el valle de México que resolvieran el peligro de las inundaciones. ${ }^{51}$ Asimismo el ingeniero introdujo la promesa de la fuerza nuclear con fines pacíficos en el tratamiento de aguas salobres y negras y en la producción de energía eléctrica, usando como fuente de potencia un reactor. ${ }^{52}$

El proyecto se aprobó en diciembre de ese mismo año con un presupuesto inicial de 12.5 millones de pesos. ${ }^{53}$ Éste perdió impulso con el fallecimiento de Nabor Carrillo en febrero de 1967; no obstante, continuó bajo la supervisión de los ingenieros Fernando Hiriart y Roberto Graue, ${ }^{54}$ quienes luego de cuatro años de trabajos propusieron un programa tentativo de obras a realizarse en catorce años. Éste comprendía la construcción de cuatro lagos artificiales para almacenar los escurrimientos superficiales, tratar las aguas negras, y regular las avenidas de los ríos del oriente, así como la creación de un tanque de regularización entre otras obras hidráulicas. ${ }^{55}$

En el resto de los terrenos desecados se pretendía el desarrollo de la agricultura en $20.8 \mathrm{~km}^{2}$; la creación de franjas arboladas en una extensión de $10 \mathrm{~km}^{2}$, así como continuar con el negocio de la explotación de sales y la industrialización del área en una superficie de $45 \mathrm{~km}^{2}$. Además se planteaba la edificación de vivienda social en $37 \mathrm{~km}^{2} .{ }^{56}$ Esto último bajo el argumento de que, con el tiempo, los terrenos desecados "inevitablemente terminarían siendo invadidos por núcleos de poblados y construcciones

${ }^{50}$ ShcP, Proyecto Texcoco. Memoria..., p. XII.

${ }^{51}$ ShcP, Proyecto Texcoco. Memoria..., p. XII.

52 Enrique Esqueda Blas y María de la Paz Ramos Lara, "Nabor Carrillo: pionero de la energía nuclear en México", Quipu. Revista Latinoamericana de Historia de las Ciencias y la Tecnología, v. 15, n. 3, septiembre-diciembre de 2013, p. 286.

${ }^{53}$ SHCP, Proyecto Texcoco. Memoria..., p. XIV.

${ }^{54}$ shcP, Proyecto Texcoco. Memoria..., p. xIV.

${ }^{55}$ SHCP, Proyecto Texcoco. Memoria..., p. 177-182. El programa consideraba también la implementación de tuberías para salmuera y plantas de rebombeo, la construcción de pozos de agua potable y el acueducto correspondiente, así como plantas de tratamiento de aguas negras, y otras obras de encauzamiento y de control de azolves.

${ }^{56}$ sнсP, Proyecto Texcoco. Memoria..., p. 171-174. 
diversas". ${ }^{57}$ Finalmente, se reservaban $19 \mathrm{~km}^{2}$, ya fuera para la habitación popular o para la explotación agrícola. ${ }^{58}$

Este proyecto fue criticado por los miembros de la Comisión Hidrológica de la Cuenca del Valle de México, quienes mencionaban que con la muerte de Nabor Carrillo se había abandonado la idea original de construir una planta nuclear de doble propósito, "encauz[ando] sus trabajos por actividades que [eran] francamente de la competencia de la Comisión Hidrológica". ${ }^{59}$ Además, el proyecto había utilizado sus datos y revivido algunas de sus ideas ya señaladas en diversas publicaciones, pero sin tomar en cuenta la planeación regional expuesta en el Plan Hidráulico del Valle de México elaborada por dicho organismo. ${ }^{60}$

Pero la idea que causó mayor reproche fue aquella de crear áreas urbanas "para dar acomodo a la expansión demográfica que se presentaba en la zona metropolitana". ${ }^{61}$ Este uso de las tierras era precisamente uno de los que más había combatido la Comisión Hidrológica desde que fue creada, según comentaba, debido a "los grandes problemas que se habían presentado en la llamada Ciudad Netzahualcóyotl, en consecuencia, [era] absurdo auspiciar ahora la repetición de un craso error urbano que se tenía a la vista". ${ }^{62}$

Para la Comisión Hidrológica, la única propuesta que valía la pena estudiar era aquella relacionada con la construcción de cuatro vasos en el lecho del lago, en lugar de solamente uno como había propuesto este comité. No obstante, quedaba a consideración de esta entidad la viabilidad del proyecto, así como determinar la ubicación, la capacidad, el funcionamiento de los lagos y su prelación en la obra. ${ }^{63}$

La idea de la creación de lagos artificiales también se discutió en la Sociedad Forestal Mexicana, en 1957, se formó el Comité Coordinador Privado para la protección de las Zonas Lacustres, con el fin de estudiar los recursos hidráulicos disponibles en el valle de México y así determinar el tamaño y los usos de los cuerpos artificiales de agua. En este marco, el ingeniero Pablo Bistráin presentó "Una aportación para definir la política hidráulica del abastecimiento de agua potable de la Ciudad de México”. El

\footnotetext{
57 ShCP, Proyecto Texcoco. Memoria..., p. 183.

${ }^{58}$ SHCP, Proyecto Texcoco. Memoria..., p. 171-174.

${ }^{59}$ CHCVM, Lineamientos generales de El Plan Hidráulico..., p. 181-183.

${ }^{60}$ CHCVm, Lineamientos generales de El Plan Hidráulico..., p. 181.

${ }^{61}$ CHCVm, Lineamientos generales de El Plan Hidráulico..., p. 182.

${ }^{62}$ CHCvм, Lineamientos generales de El Plan Hidráulico..., p. 183.

${ }^{63}$ CHCvm, Lineamientos generales de El Plan Hidráulico..., p. 183.
} 
estudio sugería la creación de dos lagos artificiales, uno de 4000 ha para el fomento del turismo, y otro de 2000 ha para aumentar la producción de la planta de sales Sosa Texcoco, además de varios trabajos hidráulicos como la construcción de presas y diques para alimentar estos cuerpos de agua, así como la edificación de un cinturón forestal de $40 \mathrm{~km}$ de longitud y otras obras para la urbanización y la formación de praderas y pastizales.

El ingeniero Mario Macías Villada, por su parte, desarrolló el "Proyecto para crear en el antiguo vaso del lago de Texcoco un lugar de recreo y turismo", el cual sugería la construcción de un lago artificial de 6000 ha para practicar deportes acuáticos y también para criar especies piscícolas y aves, así como una isla de $1.3 \mathrm{~km}$ por lado en el centro de dicho lago, con el propósito de albergar el Museo de Historia Natural y edificaciones que recordaran el esplendor de la cultura prehispánica levantada sobre el fondo de los lagos, además de la creación de jardines artificiales, pastizales y bosques. ${ }^{64}$

A finales de la década de los años sesenta, la Comisión Hidrológica de la Cuenca del Valle de México, el Proyecto Texcoco y la Sociedad Forestal Mexicana coincidían en la construcción de cuerpos de agua profundos y de poca superficie expuesta para reducir las pérdidas por evaporación, así como para almacenar y regular los escurrimientos de los ríos, cuyos beneficios se traducían en el mejoramiento del clima y de la salud de la población, además del embellecimiento de la urbe. A estas obras se añadían las actividades silvícolas, agropecuarias y de industrialización de sales puestas en marcha con anterioridad. La zona del vaso de lago de Texcoco fue imaginada como productiva y acogedora, revestida de árboles y pastos, lagos con peces y aves, donde el turismo y el deporte tenían oportunidad. El cumplimiento de tales ideas implicaba la transformación de la misma zona; es decir, de las corroídas condiciones de la cuenca del valle de México bajo la luz de la ciencia y la tecnología capaz de controlar, canalizar y aprovechar el agua en un esquema que incluso podía generar ganancias económicas.

\section{Plan Lago de Texcoco}

En la década de los setenta, la relación con la naturaleza, que hasta entonces había sido de dominio, de explotación desmedida y de servicio para el

${ }^{64}$ Pablo Bistráin, Las tolvaneras del lago de Texcoco, Conagua-Aна, Fondo Aprovechamientos Superficiales, caja 2766, exp. 38699, 1965, f. 121-123. 
progreso de la humanidad, se cuestionó en diversos foros internacionales y estudios académicos que abogaban por la conservación y el mejoramiento del medio humano. ${ }^{65}$ En este contexto, los terrenos desecados y los llanos, sin vegetación, así como la polución atmosférica ocasionada por las tolvaneras, el hundimiento de la urbe, las inundaciones y la escasez de agua se veían como contrarios a la civilización y el progreso, de modo que, en un esfuerzo por converger con las exigencias internacionales respecto del cuidado de la salud y el ambiente, se llevó a cabo una serie de acciones durante el año de 1971 relacionadas con la transformación de la zona.

El 9 de marzo de 1971, el presidente Luis Echeverría (1970-1976) visitó los terrenos desecados del lago de Texcoco. Diez días después anunció la creación de una comisión para que propusiera un plan de acción capaz de transformarlos en un área útil. ${ }^{66}$ Aunque se revisaron alrededor de 50 trabajos, que en diferentes años y dependencias se habían presentado como soluciones a las tolvaneras, las inundaciones, la escasez de agua y el hundimiento, se eligió eje de la alternativa el "Proyecto Texcoco", es decir, la construcción de lagos artificiales profundos y de poca superficie expuesta, mediante el método de consolidación bombeando salmueras del subsuelo, para hundir el terreno y no tener que sacar toneladas de tierra como imaginaban Miguel Ángel de Quevedo y Adolfo Orive.

El 20 de julio, el presidente firmaba dos decretos: el primero, establecía los límites de la Zona Federal del lago de Texcoco en 14500 ha. ${ }^{67} \mathrm{Y}$ el

${ }^{65}$ Las siguientes son algunas de las reuniones más importantes: la Conferencia Europea sobre la Conservación de la Naturaleza realizada en Estrasburgo, Francia, en 1971, y la Conferencia de las Naciones Unidas sobre el Medio Humano celebrada en Estocolmo, Suecia, en 1972. Entre los trabajos más conocidos se encuentran: Silent Spring de Rachel Carson, publicado en 1962; The Limits to Growth realizado por el Instituto Tecnológico de Massachusetts, y Only One Earth: The Care and Maintenance of a Small Planet escrito por Barbara Ward y René Jules Dubos, ambos publicados en 1972. De gran importancia fueron también las imágenes de la Tierra tomadas desde el espacio exterior porque permitieron observar la vulnerabilidad del planeta.

${ }^{66}$ Secretaría de Recursos Hidráulicos (en adelante SHR), “Acuerdo por el que se constituye una comisión intersecretarial transitoria que se denominará Comisión de Estudios del Lago de Texcoco”, Diario Oficial de la Federación, v. cccv, n. 18, 20 de marzo de 1971.

${ }^{67} \mathrm{SRH}$, "Decreto por el que se fijan los límites del vaso del lago de Texcoco y se destinan a la Secretaría del Patrimonio Nacional los terrenos que se citan”, Diario Oficial de la Federación, v. CCCVII, n. 18, 21 de julio de 1971. Una década después la zona federal se redujo a 8200 hectáreas. "El 16 de noviembre de 1982 se desincorporaron —a título gratuito- a favor del Gobierno del Estado de México, 2 mil 900 hectáreas, quedando 11 mil 600 hectáreas, aproximadamente, como área de la Zona Federal. A éstas hay que restar 900 hectáreas, correspondientes a Sosa Texcoco y 2500 hectáreas, de Zona Ejidal, quedando al Plan Texcoco 
segundo, aprobaba y ordenaba la ejecución del Plan Lago Texcoco ${ }^{68}$ con una erogación de 550 millones de pesos. ${ }^{69}$ De esta forma, el gobierno asumía su poder para ordenar dichas tierras y así finalizar con los remolinos de polvo y las inundaciones, en un intento por gobernar los recursos naturales.

El desarrollo del plan contemplaba la desecación definitiva de las 5000 ha del lago de Texcoco que todavía tenían agua; en su lugar se proponía la construcción de cinco lagos artificiales en 200 ha, además de la realización de otras obras hidráulicas para mejorar y regular el movimiento de los grandes volúmenes de agua empleados en el riego y por la industria de las sales. ${ }^{70}$ Así, como la creación de sitios de pastoreo y de zonas arboladas en aproximadamente 6200 ha; la edificación de unidades habitacionales y de parques públicos, en 500 y 1000 ha, respectivamente. Para la ampliación de la industria salina se contemplaban 3650 ha, y finalmente para la expansión del aeropuerto capitalino se reservaban 950 ha. $^{71}$

El plan empezó a ver resultados hasta la década de los años ochenta con la puesta en marcha de las obras hidráulicas, cuando al ingeniero Gerardo Cruickshank García se le nombró vocal ejecutivo de la Comisión del Lago de Texcoco y posteriormente gerente general del proyecto. Los trabajos en la zona ganaron reputación entre los propios ingenieros, quienes hicieron de los suelos del lago un "gran laboratorio de ingeniería aplicada". ${ }^{72}$ Esto generó conocimiento y especializó a los geotecnistas mexicanos, pero también propició narrativas triunfalistas del ingenio técnico que permitieron y justificaron la intervención de los terrenos para llevar a cabo diversos tipos de obras, con el tiempo la idea de una central aeroportuaria en el mismo lecho del lago.

8200 hectáreas." Comisión del Lago de Texcoco, Proyecto Texcoco, México, Secretaría de Agricultura y Recursos Hidráulicos, 1983, p. 3.

${ }^{68}$ SRH, "Acuerdo por el que se aprueba el Plan Lago de Texcoco y las recomendaciones formuladas por la Comisión de Estudios a que se refieren los considerados del mismo", Diario Oficial de la Federación, v. CCCVII, n. 18, 21 de julio de 1971.

69 “Adiós a las tolvaneras", México Forestal, n. 45, n. 3, 1971, p. 23.

${ }^{70}$ Además de las siguientes obras hidráulicas: bordos y tanques de evaporación, un canal colector para los ríos del oriente y la rectificación de los ríos Churubusco y de la Compañía, también se propuso la edificación de una planta de tratamiento de aguas negras y un sistema de riego para intercambio de aguas. Y finalmente, obras de bombeo y conducción del agua potable, así como un sistema de agua para las industrias. SRH, "Plan Lago de Texcoco", Revista de Divulgación, México, v. 12, n. 2, 1972, p. 37-38.

${ }^{71}$ SRH, "Plan Lago de Texcoco...", p. 34.

72 Comisión del Lago de Texcoco, Proyecto Texcoco..., p. 4. 


\section{Las obras hidráulicas}

El lago de Texcoco dejó de existir y en su lugar se construyeron cuerpos artificiales de agua para almacenar y regular los escurrimientos de los ríos, así como para reducir las pérdidas por evaporación. El lago Nabor Carrillo, el más grande de todos, con una capacidad de 36 millones de metros cúbicos y una superficie de casi mil hectáreas, se terminó de construir en 1983. En esos años también empezaron a funcionar el Lago de Regulación Horaria y el Lago Churubusco, de 150 y 270 ha, respectivamente; la laguna de Xalapango de 240 ha, y el Lago Recreativo de 25 ha. Simultáneamente se llevaron a cabo obras para conducir y rectificar los ríos de la llamada Cuenca Tributaria del Valle de México. Estos trabajos se ampliaron y mejoraron con la inauguración de la Planta de Lodos Activados, las Lagunas Facultativas y la Planta de Tratamiento Terciario para el manejo y el tratamiento de las aguas residuales, ${ }^{73}$ así como con la creación de los vasos El Fusible y Laguna Colorada, los drenes Chimalhuacán I y Chimalhuacán II, entre otras canalizaciones y presas de control en los ríos llevadas a cabo durante los siguientes lustros.

El éxito del Plan Lago de Texcoco se tradujo en la creación de dicha infraestructura hidráulica para llevar a cabo la función del lago, pero también para encauzar y controlar las aguas pluviales y residuales según los usos y las necesidades de la urbe, por lo que estas obras se conectaron con aquellas realizadas en la ciudad para interceptar, conducir y alejar el líquido (Desviación Combinada, Nuevo Túnel de Tequixquiac, Interceptor Poniente y las relacionadas con el Drenaje Profundo), así como con los sistemas Lerma y Cutzamala. A este tipo de trabajos se les otorgó un gran valor, pues se pensó que con ellos se forjaban las condiciones necesarias para el desarrollo de la metrópoli, en tanto garantizaban su subsistencia y aumentaban el nivel de vida de sus habitantes, de modo que se les consideró esenciales para su funcionamiento y el único medio para la utilización del agua.

Esta manera de resolver los problemas relacionados con las inundaciones, el hundimiento y la escasez de agua, nacida con el Desagüe del Valle de México a principios de siglo y perpetuada hasta el día de hoy, constituye lo que Manuel Perló denomina el paradigma porfiriano, el cual privilegia la construcción y el mantenimiento de magnas infraestructuras hidráulicas. ${ }^{74}$

${ }^{73}$ Cruickshank, Proyecto Lago de Texcoco..., p. 96-108.

${ }^{74}$ Perló, El paradigma porfiriano..., p. 276. Este autor y Arsenio González desarrollaron en concepto de región hidropolitana para referirse a las obras que tanto expulsan el agua de la cuenca como aquellas que la importan, y así subrayar las interacciones materiales y socia- 


\section{La Zona Federal del Lago}

Para los años noventa la Zona Federal del Lago, considerada a lo largo del siglo un auténtico páramo, había logrado ser rescatada de la miseria de sus tierras, según los resultados del Proyecto Lago de Texcoco, en gran medida debido a los programas de pastización y reforestación iniciados en 1972 y 1981, respectivamente, los que cumplieron con el viejo anhelo de la cubierta vegetal para finalizar con las tolvaneras. "De 1973 a 1998 se plantaron 25 millones de árboles"75 y se revistieron alrededor de 6000 ha con el pasto salado Distichlis spicata, una especie nativa adecuada para crecer en los suelos salinos y sódicos.

Estos trabajos se complementaron con la construcción de un parque de 40 ha para el desarrollo y producción del ciervo rojo de Nueva Zelanda, un centro de producción caballar e infraestructura para la cría de ganado vacuno. ${ }^{76} \mathrm{~A}$ la par se desarrolló el programa de piscicultura, que en su mejor época contó con 11 estanques rústicos de $800 \mathrm{~m}^{2}$, los que producían 5 toneladas al año de carpa y tilapia. La introducción de estas especies estuvo vinculada con la idea de aprovechar los terrenos y contribuir a mejorar la alimentación de los habitantes cercanos a la zona. La conservación del pescadito amarillo de gran valor nutricional, el charal y otras especies propias de la zona que constituían parte de la dieta de los pobladores originarios no se consideraron una prioridad, pero se continuaron desarrollando; es el caso del ahuautle, el acocil, las pupas y la espirulina. ${ }^{77}$

La expectativa de hacer de esta zona un lugar de recreo y diversión trajo consigo la organización de ciertas actividades, como la carrera anual del lago, de $15 \mathrm{~km}$ a lo largo del bordo perimetral del Lago Nabor Carrillo, así como el aeromodelismo, la pesca deportiva, el remo y el canotaje, ${ }^{78}$ de

les entre las cuencas hidrológicas involucradas (valle de México, Alto Lerma, Cutzamala y Tula) y los diferentes niveles de gobierno de los estados participantes (Ciudad de México, Michoacán e Hidalgo). Manuel Perló Cohen y Arsenio Ernesto González Reynoso, ¿Guerra por el agua en el valle de México? Estudios sobre las relaciones hidráulicas entre el Distrito Federal y el Estado de México, México, Universidad Nacional Autónoma de México, Coordinación de Humanidades, Programa Universitario de Estudios sobre la Ciudad, 2009.

${ }^{75}$ Cruickshank, Proyecto Lago de Texcoco..., p. 111.

${ }^{76}$ Cruickshank, Proyecto Lago de Texcoco..., p. 133.

${ }^{77}$ Salomón Shamosh Halabe, Historia, nutrición, salud y ecología para generar estrategias de comunicación sobre la espirulina (A. máxima), tesis de maestría en Filosofía de la Ciencia, México, Universidad Nacional Autónoma de México, 2010.

${ }^{78}$ Cruickshank, Proyecto Lago de Texcoco..., p. 124-126. 
poco éxito debido al costoso equipo especializado para su ejecución y porque éstas no estaban conectadas con las prácticas de los pobladores. No obstante, el acceso a la zona estaba limitado por el órgano gestor; esto quiere decir que se requería de un permiso para poder acceder, lo que impidió la apropiación de este espacio por parte de los habitantes; este cuidado se explica debido al temor de que los terrenos fueran invadidos y comercializados de manera ilegal como ocurrió con Ciudad Nezahualcóyotl. ${ }^{79}$

Entre los resultados más celebrados derivados del restablecimiento de la zona lacustre, en concreto del llenado del lago Nabor Carrillo fue el desarrollo y reproducción de las aves acuáticas locales y migratorias, lo que le valió al programa un gran reconocimiento internacional en los siguientes años. ${ }^{80}$ La caza fotográfica y el club de observadores de aves nacieron del interés por presenciar el vuelo de las aves al amanecer durante el otoño y el invierno. Estas importantes poblaciones de aves de hasta 200000 ejemplares de 250 especies han sido el principal argumento de diversos grupos para solicitar la conservación de dicha zona en el siglo XXI. ${ }^{81}$

No obstante, la Zona Federal del Lago también dio cabida a la disposición final de los desechos procedentes de la ciudad de México. En febrero de 1985 se puso en operación el relleno sanitario denominado Bordo Poniente. ${ }^{82}$ Los tiraderos a cielo abierto, improvisados en terrenos baldíos que abundaban en las periferias y colonias populares, dada la falta de un sitio adecuado y de un sistema de limpia ordenado se sustituyeron con las 233 ha dispuestas en el oriente de la metrópoli para este fin. El exvaso del lago de Texcoco volvió a recibir las inmundicias de la civilización.

Los albores del siglo xxi trajeron consigo renovados proyectos para esta área. La peripecia de edificar una gran terminal aeroportuaria de más de 4000 ha en el lecho del antiguo lago de Texcoco se anunció durante el sexenio de Vicente Fox (2000-2006). En octubre de 2001 se expropiaron más de 5000 ha pertenecientes a los municipios de Atenco, Texcoco y Chimalhuacán para, entre otras cosas, la construcción del nuevo aeropuerto de la ciudad de México y sus obras complementarias. Este proyecto se canceló en agosto de 2002 con la anulación de los decretos expropiatorios, en gran medida por la oposición de los propietarios de las tierras y de diversas

${ }^{79}$ Linares, Ciudad Nezahualcóyotl, de la pobreza a la globalización..., p. 74.

${ }^{80}$ José Luis Alcántara, Patricia Escalante, Patricia Ramírez, Alejandra Salazar, Plan de gestión para la conservación de las aves en Texcoco, México, 2019, p. 7.

${ }^{81}$ Alcántara, Escalante, Ramírez, Salazar, Plan de gestión..., p. 8.

${ }^{82}$ Cruickshank, Proyecto Lago de Texcoco..., p. 119-120. 
organizaciones sociales y ecologistas, así como del Gobierno de la Ciudad de México y del Ayuntamiento de Texcoco ${ }^{83}$ Más tarde durante la administración de Enrique Peña Nieto (2012-2018), en septiembre de 2015, inició la construcción del nuevo Aeropuerto Internacional de la Ciudad de México, constituido por seis pistas y un edificio central. Esta obra se suspendió oficialmente en enero de 2019, luego de que los participantes de una consulta popular, realizada en octubre de 2018, eligieran reacondicionar el actual aeropuerto y el de Toluca y construir dos pistas en la Base Aérea Militar de Santa Lucía. No obstante, el debate sigue vigente, por lo que queda pendiente la realización de una investigación que muestre la disputa suscitada y ofrezca un análisis de lo ocurrido en las dos últimas décadas.

\section{A manera de conclusión}

A lo largo de casi un siglo ingenieros, políticos y otros expertos se empeñaron en desaparecer por completo el último remanente del lago de Texcoco y en su lugar construir profundos lagos de poca superficie expuesta para almacenar y regular las aguas pluviales y residuales. ${ }^{84}$ Esto fue con el fin de resolver los problemas sanitarios y ambientales (inundaciones, tolvaneras, hundimiento y escasez de agua) consecuencia de las obras del desagüe y de la explotación de los mantos acuíferos, en una interminable paradoja en la que se hacen obras por el agua y contra el agua.

En la primera mitad del siglo, básicamente, cuatro ideas dominaron el imaginario de lo que podía hacerse en aquellos terrenos. La primera vio unas tierras fértiles dedicadas a la explotación agrícola. La segunda imaginó una planicie verde, reforestada y también pastizada. La tercera optó por la industrialización de las sales, y la cuarta abogó por la recuperación de la cuenca lacustre. El deseo de hacerlas rentables y generar ganancias a partir de su transformación ha estado presente desde su desecación.

${ }^{83}$ Enrique Moreno Sánchez, "El aeropuerto y el movimiento social de Atenco", Convergencia, v. 17, n. 52, enero-abril de 2010, p. 79-96.

${ }^{84}$ Mientras que en Dallas algunos grupos de ciudadanos han pedido con urgencia durante poco más de 70 años que se ponga un lago en medio de su ciudad, debido a la belleza natural de un cuerpo de agua, lo que es moralmente enaltecedor para la vida cívica. Iván Illich, " $\mathrm{H}_{2} \mathrm{O}$ y las aguas del olvido. Reflexiones sobre la historicidad de la materia, aquello de lo que las cosas están hechas”, en Obras reunidas, revisión de Valentina Borremans y Javier Sicilia, México, Fondo de Cultura Económica, 2006, p. 337. 
Para mediados de siglo, las ideas anteriores dieron pie a una serie de proyectos que, no solamente dieron seguimiento a los trabajos de bonificación, silvicultura e industrialización de las sales, sino que se perfeccionaron; es el caso del desarrollo de los lagos artificiales y de las obras hidráulicas. Asimismo, los planes incorporaron la promesa de la energía nuclear mediante la introducción de un reactor para generar energía eléctrica y potabilizar el agua, el desarrollo de núcleos de vivienda e incluso la intención de hacer de la zona, un sitio de turismo y descanso para los habitantes de la metrópoli, sin que estas propuestas llegaran a materializarse.

Este corroído espejo de agua ha sido reflejo de los anhelos y las ambiciones de expertos y gestores con la capacidad de decidir sobre éste, por lo que poco tomaron en cuenta la opinión de los pueblos circundantes y la existencia de otros seres vivos dependientes de ese entorno. No obstante, dichos proyectos se vieron limitados por las especiales características de compresibilidad del subsuelo y su alto contenido salino. De ahí que la bonificación se confinara a la zona sudoeste y que se comparara con sembrar sobre un comal; que la cubierta vegetal requiriera cuidado constante, al punto de parecer una tarea interminable, y por lo mismo el poco éxito de los proyectos, excepto por el afortunado desarrollo de la industria Sosa Texcoco en la zona norte, donde la concentración de sal duplicaba la del agua del mar.

La perseverancia de casi un siglo por transformar estas tierras, en un sitio útil y productivo, dio cabida, por un lado, para la realización de magnas obras hidráulicas, responsables tanto de desecar el lago como de crear nuevos cuerpos de agua. "El sol no se bebió el lago, no lo sorbió la tierra", ${ }^{85}$ fueron los trabajos hidráulicos, los que, empecinados en controlar, canalizar y aprovechar el agua, crearon aquella "Terramuerta [...] lodosa cenipolva pedrósea" ${ }^{86}$ como describía Octavio Paz a aquella zona.

Por otro lado, permitieron la experimentación y la introducción de plantas, árboles y animales foráneos, con la esperanza de cambiar su naturaleza y generar recursos, sin que ello ocurriera realmente, pues, al cabo de unos meses, durante el estiaje, la tierra salina se agrietaba y el polvo se levantaba, mientras que en época de lluvias los terrenos se encharcaban.

${ }^{85}$ Octavio Paz, "Petrificada petrificante", en Obras selectas de premios Nobel: Octavio Paz, 1990, Barcelona, Planeta, 1994.

${ }^{86}$ Paz, "Petrificada petrificante...." 
Las tierras descubiertas por el lago han sido notablemente intervenidas también para embellecerlas. No obstante, han continuado recibiendo las inmundicias de la ciudad, pues a cielo abierto se encontraban el Canal del Desagüe y las plantas de tratamiento de las aguas negras, además de las toneladas de residuos sólidos que conformaban el relleno sanitario del Bordo Poniente.

En los albores del siglo xxi, el área federal del lago de Texcoco quedó rodeada por barrios, colonias y fraccionamientos, que se incorporaron al ámbito metropolitano, dado el crecimiento de la capital. Así, de las 27000 y 29000 ha que, se calculaba, conformaban esta zona, quedaba una tercera parte, 8200 ha: un oasis de tierras sin urbanizar, sobre las que se empezó a construir un nuevo tipo de obra: el aeropuerto.

\section{FUENTES}

Archivos

Comisión Nacional del Agua, Archivo Histórico y Biblioteca Central del Agua, Fondo Aprovechamientos Superficiales y Fondo Consultivo Técnico.

Secretaría de Cultura del Gobierno de la Ciudad de México, Museo Archivo de la Fotografía.

\section{Hemerografía}

El Nacional.

El Universal.

Proceso.

\section{Documentos}

Comisión del Lago de Texcoco, Proyecto Texcoco, México, Secretaría de Agricultura y Recursos Hidráulicos, 1983.

Comisión Hidrológica de la Cuenca del Valle de México, Lineamientos generales de El Plan Hidráulico para la Cuenca del Valle de México (alternativa 19601990), México, Secretaría de Recursos Hidráulicos, 1966. 
Comisión Hidrológica de la Cuenca del Valle de México, Plan Hidráulico para la cuenca del Valle de México (Alternativa 1970-2000), México, Secretaría de Recursos Hidráulicos, 1970.

Departamento Agrario, "Acuerdo que previene se dé preferencia a los campesinos y ejidatarios de los pueblos circunvecinos, en la ejecución de las obras de bonificación del lago de Texcoco", Diario Oficial de la Federación, v. cx, n. 31, 7 de octubre de 1938.

Departamento del Distrito Federal, Memoria de obras del Sistema de Drenaje Profundo del Distrito Federal, México, Departamento del Distrito Federal/Talleres Gráficos de la Nación, 1975.

Dirección General de Construcción y Operación Hidráulica, Plan maestro de drenaje de la Zona Metropolitana de la Ciudad de México: 1994-2010, México, Departamento del Distrito Federal, 1995.

Dirección General de Obras hidráulicas, Plan general para resolver los problemas del hundimiento, las inundaciones y el abastecimiento de agua potable de la Ciudad de México, México, Departamento del Distrito Federal, 1954.

Secretaría de Agricultura y Fomento, "Decreto por el cual se previene que deberán ejecutarse las obras para el drenaje, bonificación e irrigación de los terrenos desecados y desecables del lago de Texcoco", Diario Oficial, v. LXviII, n. 39, 19 de octubre de 1931.

Secretaría de Hacienda y Crédito Público, Proyecto Texcoco: Memoria de los trabajos realizados y conclusiones, México, Secretaría de Hacienda y Crédito Público, 1969.

Secretaría de Recursos Hidráulicos, "Acuerdo que crea la Comisión Hidrológica de la Cuenca del Valle de México”, Diario Oficial de la Federación, v. CLXXXVII, n. 16, 19 de julio de 1951.

"Acuerdo por el que se constituye una comisión intersecretarial transitoria que se denominará Comisión de Estudios del Lago de Texcoco”, Diario Oficial de la Federación, v. cccv, n. 18, 20 de marzo de 1971.

"Decreto por el que se fijan los límites del vaso del lago de Texcoco y se destinan a la Secretaría del Patrimonio Nacional los terrenos que se citan”, Diario Oficial de la Federación, v. Cccvir, n. 18, 21 de julio de 1971.

"Acuerdo por el que se aprueba el Plan Lago de Texcoco y las recomendaciones formuladas por la Comisión de Estudios a que se refieren los considerados del mismo", Diario Oficial de la Federación, v. CcCviı, n. 18, 21 de julio de 1971.

“Plan Lago de Texcoco”, Revista de Divulgación, v. 12, n. 2, México, 1972. 


\section{Bibliografía}

"Adiós a las tolvaneras", México Forestal, v. 45, n. 3, 1971, p. 23-24.

Alcántara, José Luis, Patricia Escalante, Patricia Ramírez y Alejandra Salazar, Plan de gestión para la conservación de las aves en Texcoco, México, 2019.

Agostoni Urencio, Claudia, Monuments of Progress. Modernization and Public Health in Mexico City, 1876-1910, Calgari/Boulder, University of Calgary Press/ University Press of Colorado/Universidad Nacional Autónoma de México, Instituto de Investigaciones Históricas, 2003.

Balbontín, Manuel, "El lago de Texcoco", Boletín de la Sociedad Mexicana de Geografía y Estadística, 1873, p. 372-377.

BirRichaga Gardina, Diana, y María del Carmen Salinas Sandoval (coords.), Cartografía hidráulica del Estado de México, México, Fondo Editorial Estado de México/El Colegio de Michoacán/El Colegio Mexiquense, 2016.

BOYER, Richard Everett, La gran inundación. Vida y sociedad en México, 1629-1638, México, Secretaría de Educación Pública, 1975.

Bucay, Benito, "Apuntes de historia de la química industrial en México", Revista de la Sociedad Química de México, v. 45, n. 3, 2001, p. 136-142.

Candiani, Vera S., Dreaming of Dry Land. Environmental Transformation in Colonial Mexico City, Stanford, Stanford University Press, 2014.

Carrillo, Nabor, El hundimiento de la ciudad de México y Proyecto Texcoco, México, Secretaría de Hacienda y Crédito Público, 1969.

Carson, RaChel, Primavera silenciosa, Barcelona, Grijalbo, 1980.

Cházaro García, Laura, "El lago de Texcoco y la ciudad de México: entre las diferencias políticas y la higiénica igualdad”, en Eulalia Ribera Carbó, Héctor Mendoza Vargas y Martín Pere Sunyer (coords.), La integración del territorio en una idea de Estado. México y Brasil, 1821-1946, México, Universidad Nacional Autónoma de México, Instituto de Geografía/Instituto de Investigaciones Dr. José Luis Mora, 2007, p. 423-441.

Cruickshank García, Gerardo, "Hacia una gestión integral de la cuenca del valle de México”, en Gabriel Quadri de la Torre (comp.), Aguas residuales de la zona metropolitana de la ciudad de México, México, Friedrich Ebret/Departamento del Distrito Federal, 1989, p. 131-137.

, Proyecto Lago de Texcoco. Rescate hidrológico, México, Sistemas Gráficos, 1998.

Cruickshank Villanueva, Carlos, "Gerardo Cruickshank García. No hay lugar para rendirse”, Geotecnia. Órgano oficial de la Sociedad Mexicana de Ingeniería y Geotécnica, n. 242, diciembre de 2016-febrero de 2017, p. 7-11. 
Espinosa Pineda, Gabriel, El embrujo del lago. El sistema lacustre de la cuenca de México en la cosmovisión mexica, México, Universidad Nacional Autónoma de México, Instituto de Investigaciones Históricas, Instituto de Investigaciones Antropológicas, 1996.

EsQueda Blas, Enrique y María de la Paz Ramos Lara, "Nabor Carrillo: pionero de la energía nuclear en México", Quipu. Revista Latinoamericana de Historia de las Ciencias y la Tecnología, v. 15, n. 3, septiembre-diciembre de 2013, p. 285-319. García LunA, Margarita, Nezahualcóyotl: tierras que surgen de un desequilibrio ecológico, México, Gobierno del Estado de México, 1990.

GonzÁlez Obregón, Luis, Memoria histórica, técnica y administrativa de las obras del desagüe del valle de México, 1449-1900, México, Tip. de la Oficina Impresora de Estampillas, 1902.

Gurría LACroix, Jorge, El desagüe del valle de México durante la época novohispana, México, Universidad Nacional Autónoma de México, 1978.

Huerta GonzÁlez, Rodolfo, "Agua, bosques y capitalismo: la región de Chalco, 1890-1940”, en Nicolás Hiernaux, Alicia Lindón Villoria y Jaime Noyola Rocha (coord.), La construcción social de un territorio emergente, México, El Colegio Mexiquense/Ayuntamiento Valle de Chalco Solidaridad, 2000.

ILliCH, Iván, " $\mathrm{H}_{2} \mathrm{O}$ y las aguas del olvido. Reflexiones sobre la historicidad de la materia, aquello de lo que las cosas están hechas”, en Obras reunidas, revisión de Valentina Borremans y Javier Sicilia, México, Fondo de Cultura Económica, 2006, p. 339-419.

Linares Zarco, Jaime, Ciudad Nezahualcóyotl, de la pobreza a la globalización económica y la saturación urbana, México, Universidad Nacional Autónoma de México, Facultad de Estudios Superiores Aragón, 2013.

Meadows, Donella H., Dennis L. Meadows, Jorgen Randers y William W. Behrens III, Los límites del crecimiento. Informe al Club de Roma sobre el predicamento de la humanidad, México, Fondo de Cultura Económica, 1972.

Miranda Pacheco, Sergio, "Urbe inmunda: poder y prejuicios socioambientales en la urbanización y desagüe de la ciudad y valle de México en el siglo xıx", en Élodie Dupey y Guadalupe Pinzón Ríos (coord.), De olfato. Aproximaciones a los olores en la historia de México, México, Secretaría de Cultura/Fondo de Cultura Económica, 2018.

Moreno SÁnchez, Enrique, "El aeropuerto y el movimiento social de Atenco", Convergencia, v. 17, n. 52, enero-abril de 2010, p. 79-96.

Murillo F., Rodrigo, "Comportamiento del suelo y obras en el ex Lago de Texcoco”, Geotecnia, Órgano oficial de la Sociedad Mexicana de Ingeniería y Geotécnica, n. 238, diciembre de 2015-febrero de 2016, p. 20-35. 
Neymet, Agustín de, "Inundaciones", Ingeniería Hidráulica en México, v. 6, n. 2, 1952, p. 2-4.

Orive Alba, Adolfo, "Los problemas del valle de México”, Ingeniería Hidráulica en México, v. 6, n. 2, 1952 p. 5-13.

Paz, Octavio, "Petrificada petrificante", en Obras selectas de premios Nobel: Octavio Paz, 1990, Barcelona, Planeta, 1994.

Peimbert, Ángel, Augusto Petriccioli y Luis Mac Gregor, "Memoria descriptiva del proyecto del Parque Agrícola de la ciudad de México”, Planificación, v. 2, n. 5, octubre-noviembre de 1934, p. 39.

Perló, Manuel, El paradigma porfiriano: historia del desagüe del valle de México, México, Universidad Nacional Autónoma de México, Programa Universitario de Estudios sobre la Ciudad, Instituto de Investigaciones Sociales/Miguel Ángel Porrúa, 1999.

Perló Cohen, Manuel y Arsenio Ernesto González Reynoso, ¿Guerra por el agua en el valle de México? Estudios sobre las relaciones hidráulicas entre el Distrito Federal y el Estado de México, México, Universidad Nacional Autónoma de México, Coordinación de Humanidades, Programa Universitario de Estudios sobre la Ciudad, 2009.

Ponce, Armando, “Texcoco salvación o desastre del D. F.”, Proceso, n. 1308, 2001, p. 48-52.

Quevedo, Miguel Ángel de, "Las polvaredas de los terrenos tequezquitosos del antiguo lago de Texcoco y los procedimientos de enyerbe para remediarlas", México Forestal v. 5, n. 5-6, 1927, p. 39-52.

, "Los desastres de la deforestación en el valle y ciudad de México", México Forestal, v. 7, n. 6, 1929, p. 116-127.

, "Las resoluciones de los Congresos Internacionales de Higiene de 1900 en París y de 1907 en Berlín”, México Forestal, v. 18, n. 3-4, 1940, p. 19-24.

Reyes, Alfonso, "Palinodia del polvo", en José Luis Martínez (comp.), Visión de Anáhuac y otros ensayos, 3a. ed., México, Fondo de Cultura Económica, 2001, p. 276-284.

Ríos Elizondo, Roberto (ed.), Memoria de obras del Sistema de Drenaje Profundo del Distrito Federal, 4 v., México, Departamento del Distrito Federal, 1975.

Rulfo, Juan, El llano en llamas, México, RM/Fundación Juan Rulfo, 2018.

Shamosh Halabe, Salomón, Historia, nutrición, salud y ecología para generar estrategias de comunicación sobre la espirulina (A. máxima), tesis de maestría en Filosofía de la Ciencia, México, Universidad Nacional Autónoma de México, 2010.

Serrato, Gilberto, "Aniversario de los primeros xxv años de vida de la revista México Forestal y síntesis de la historia del Servicio Forestal Mexicano”, México Forestal v. 26, n. 1-4, 1948, p. 3-4. 
Tortolero Villaseñor, Alejandro, De la coa a la máquina de vapor, México, Siglo XXI, 1998.

VITz, Matthew, A City on a Lake. Urban Political Ecology and the Growth of Mexico City, Durham (North Carolina), Duke University Press, 2018.

WARD, Barbara y René Dubos, Una sola tierra. El cuidado y conservación de un pequeño planeta, México, Fondo de Cultura Económica, 1972. 





Figura 1. Obras del lago de Texcoco. Plano general de las obras.

Fuente: Mariano Barragán, Proyecto de bonificación de las tierras del vaso del lago de Texcoco, 1913, Conagua-AнA, Fondo Consultivo Técnico, caja 200, exp. 1689, f. 11 


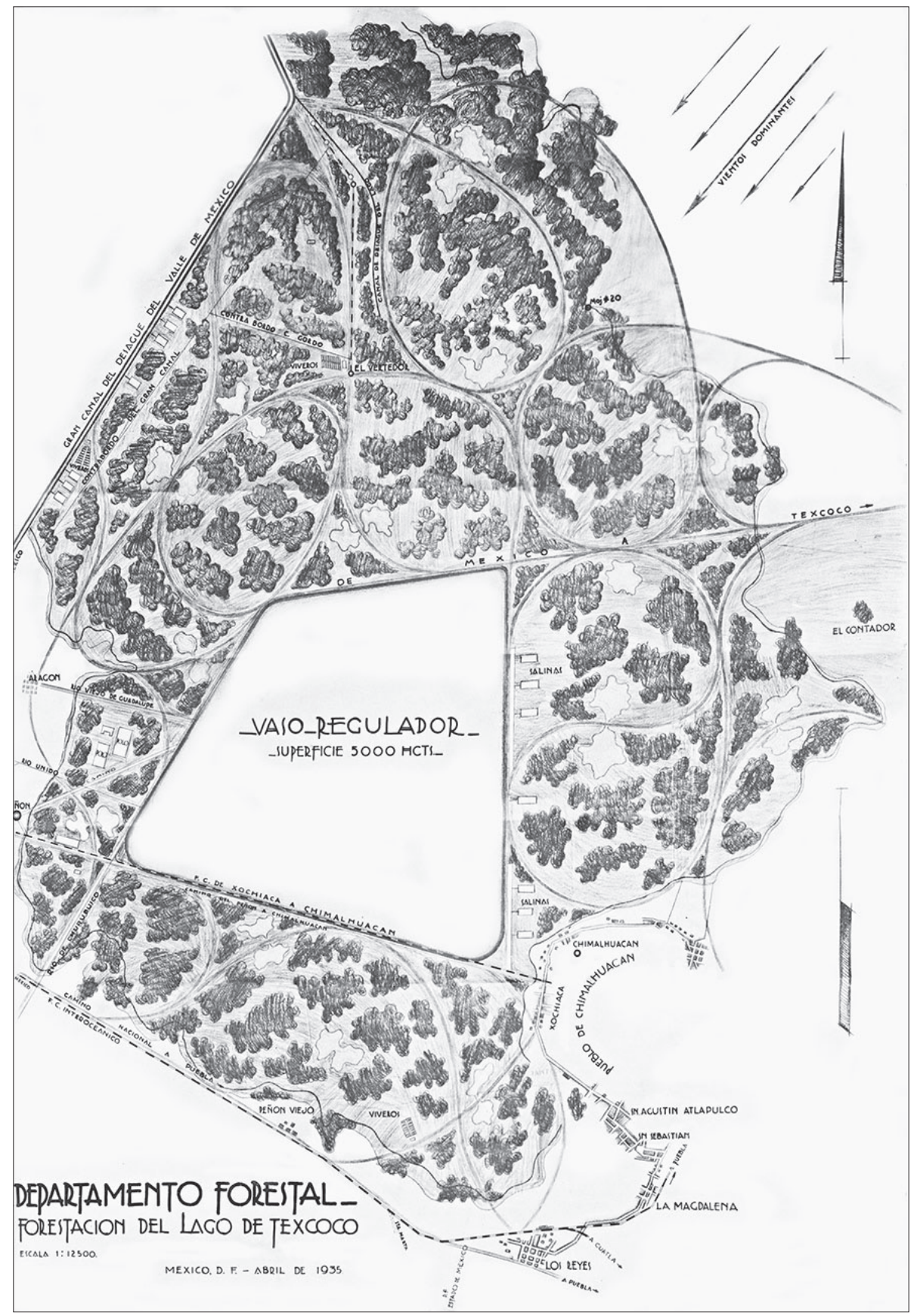

Figura 2. Reforestación del lago de Texcoco, abril 1936.

Fuente: Secretaría de Cultura del Gobierno de la Ciudad de México, Museo Archivo de la Fotografía, plano 005025-003 


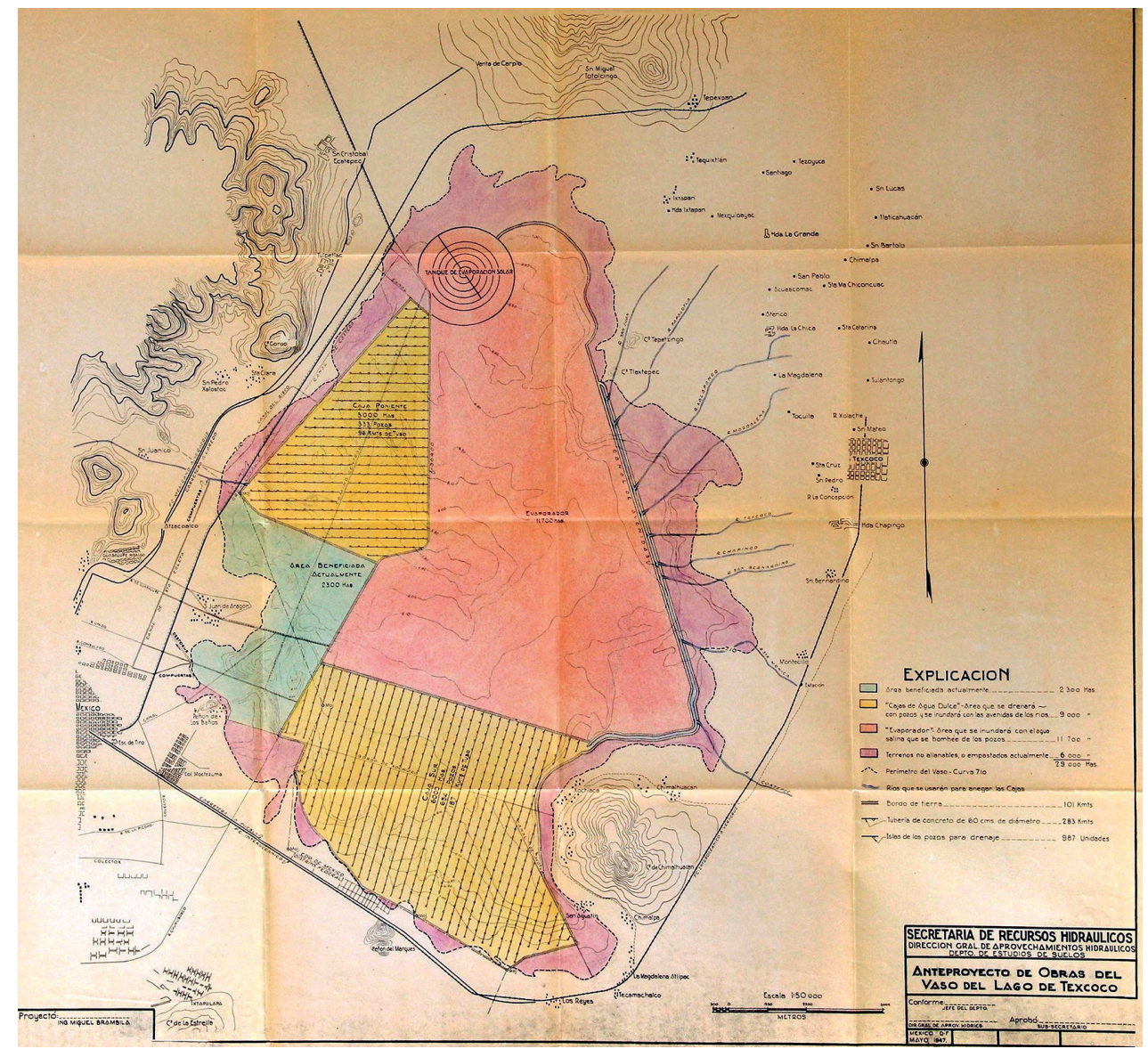

Figura 3. Anteproyecto de Obras del Vaso del Lago de Texcoco. Fuente: Miguel Brambila, Lineamientos generales para el proyecto de obras del vaso del lago de Texcoco, 1947, Conagua-Aна, Fondo Consultivo Técnico, caja 177 , exp. 1424 , f. 20 
EL UNIVERSAL

La Reconquista Ecológica del Valle de México

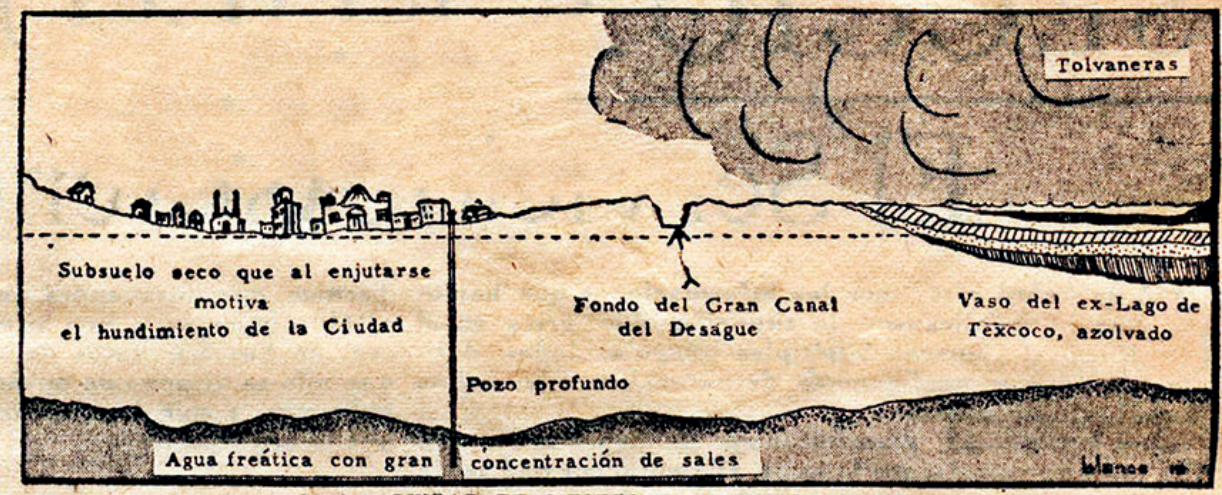

1. LA CIUDAD DE MEXICO EN LA ACTUALIDAD

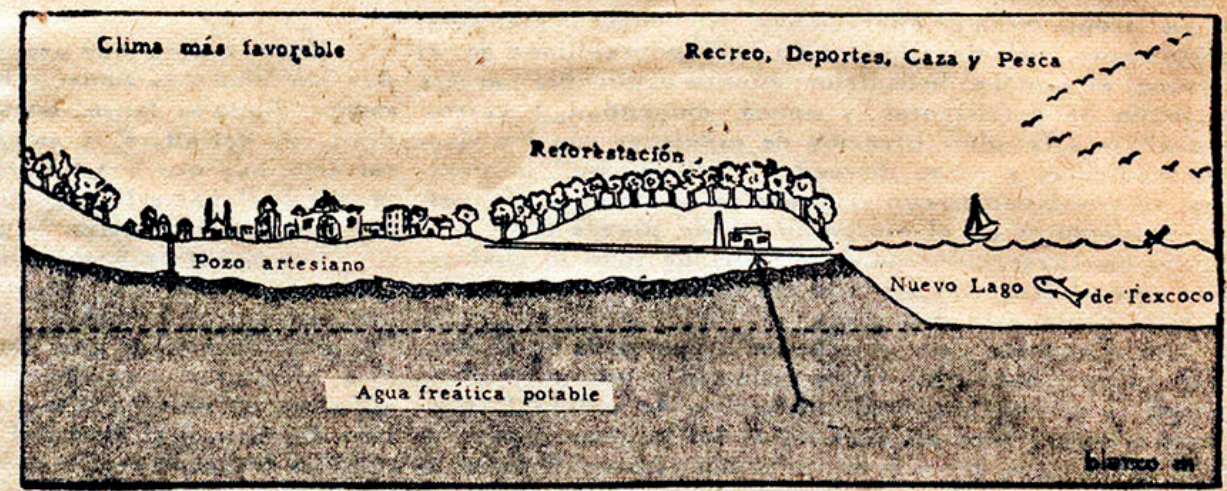

2 - LA CIUdAD DE MEXICO AL RESTABLECERSE EL LAGO DE TEXCOCO

Figura 4. La reconquista ecológica del Valle de México.

Fuente: Gonzalo Blanco Macías, "La reconquista ecológica del valle de México", El Universal, 29 de noviembre de 1951, p. 4. Elaboración de Gonzalo Blanco. Conagua-AHA, Fondo Aprovechamientos Superficiales, caja 2766, exp. 38699, f. 48 


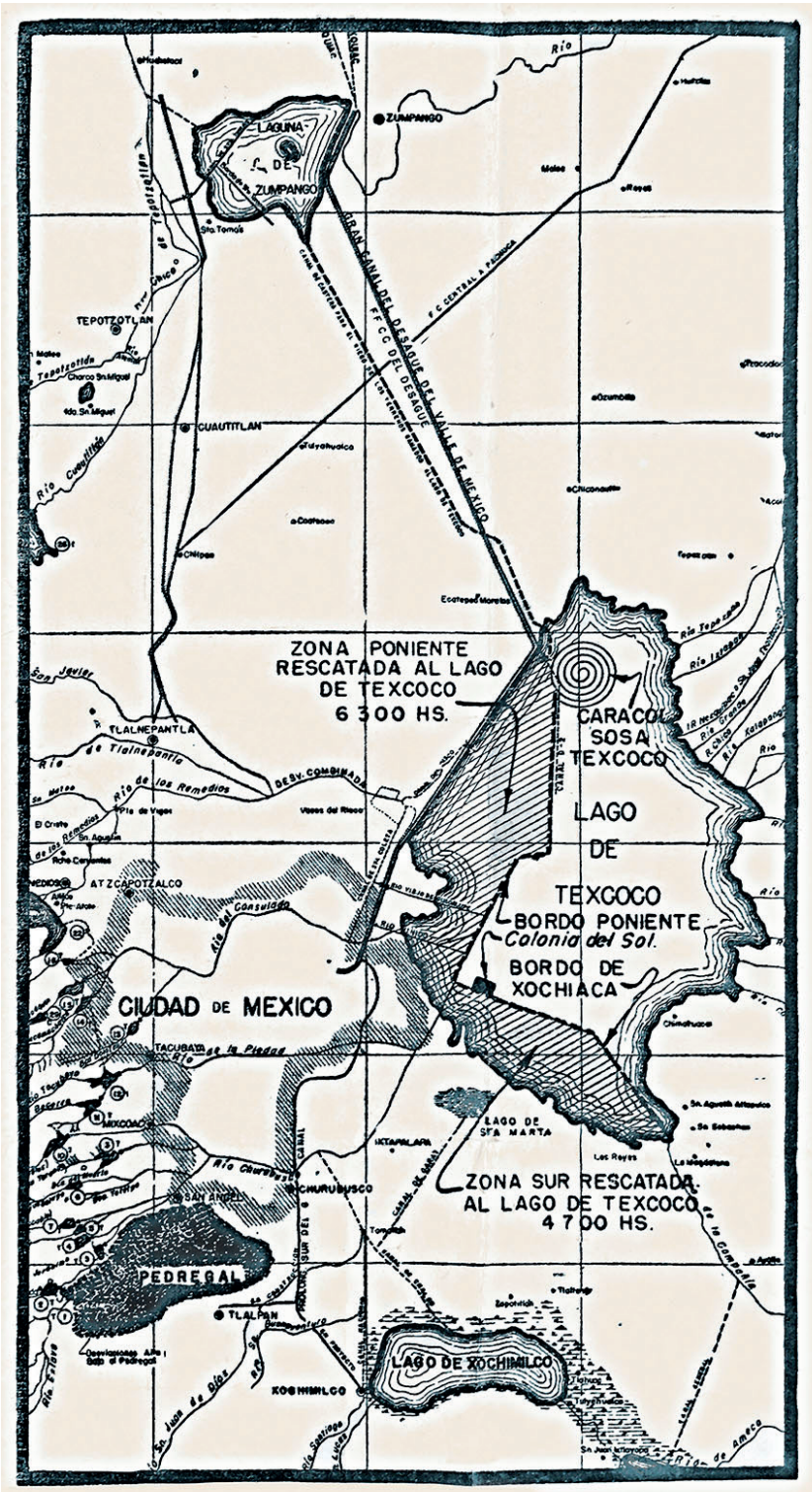

Ahora, merced a los trabajos realizados por la Secretaria de Recursos Hidráulicos, ha disminuido en 11,000 hectáreas la superficie del "centro de aprovisionamiento" de las tolvaneras, por el sencillo expediente de llenar de agua el lago hasta el limite de los bordos señalados en el mopa. Como ya habia 5,000 hectáreas con agua, la supen ficie total Fidratada de $T$ excoco es ya de $16,000 \mathrm{Hs}$

Figura 5. Trabajos realizados por la Secretaría de Recursos Hidráulicos. Fuente: Adrián García, "México comienza a recuperar sus viejos lagos devolviendo a su cuna lacustre el agua que le quitó...", El Universal. Revista de la semana, 12 de abril de 1953, p. 5. Conagua-AнA, Fondo Consultivo Técnico, 


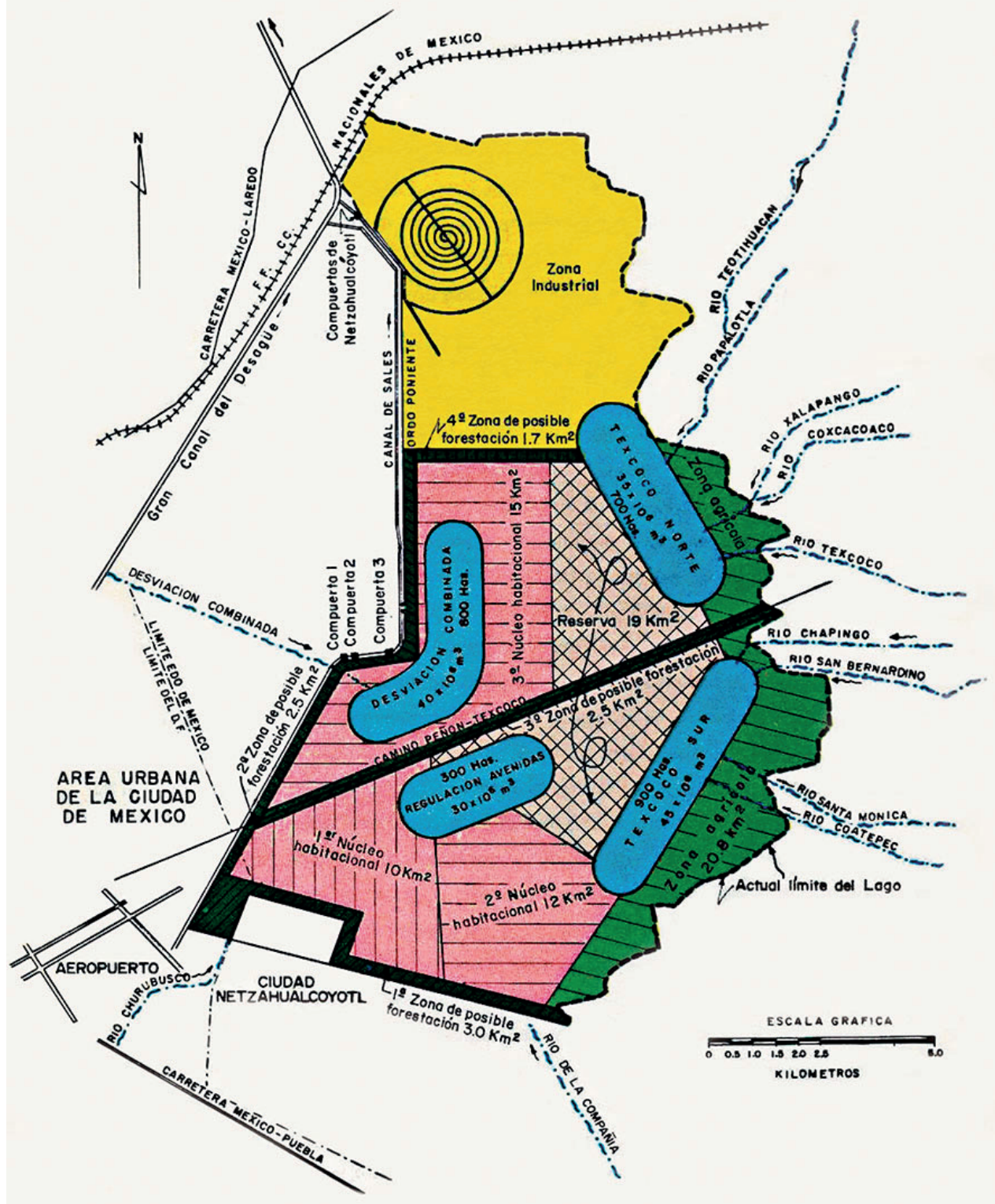

FIG 72. DESARROLLO URBANISTICO DE LA ZONA FEDERAL DEL LAGO

Figura 6. Desarrollo urbanístico de la Zona Federal del lago.

Fuente: SHCP, Proyecto Texcoco. Memoria de los trabajos realizados y conclusiones, México, 1969, p. 170 


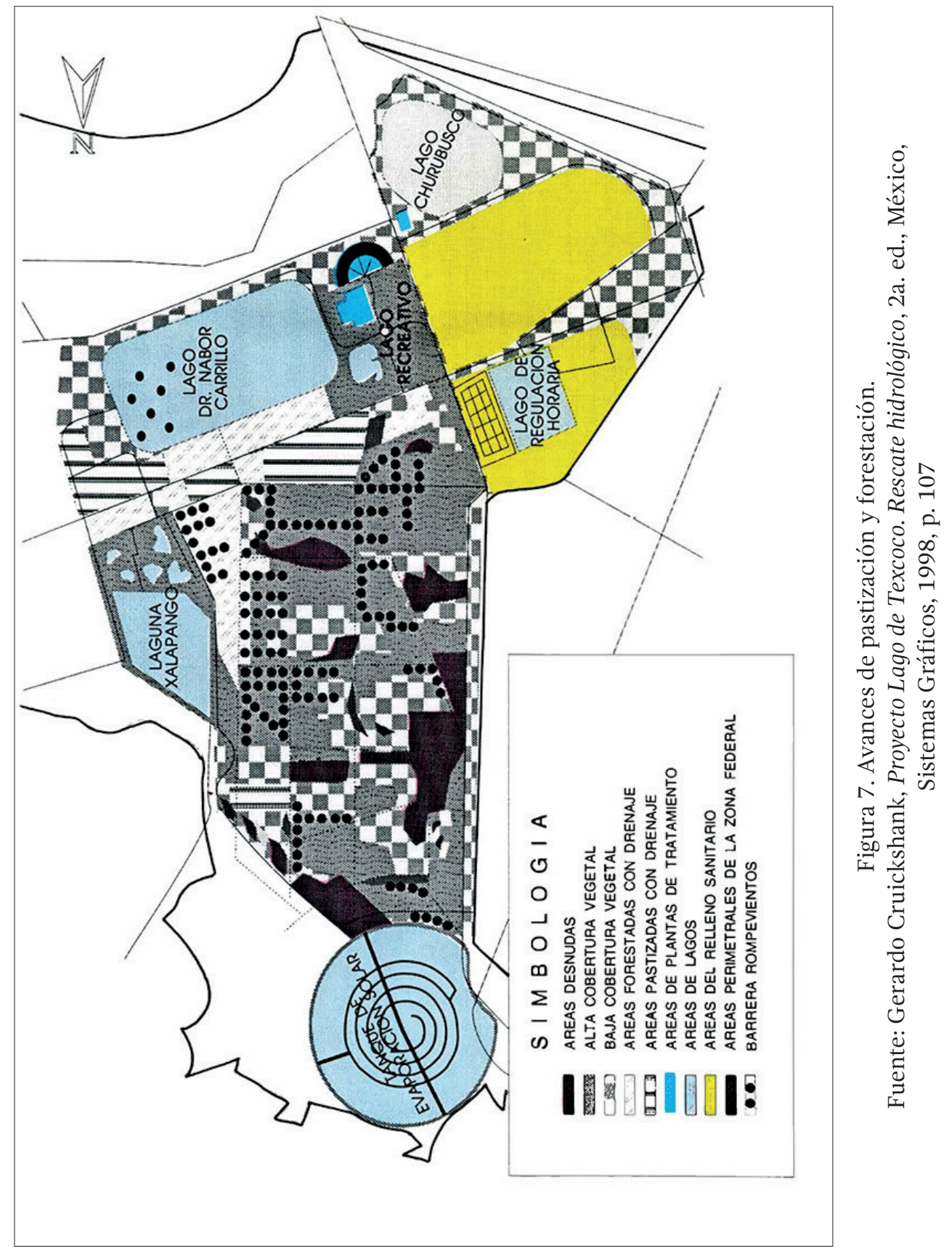




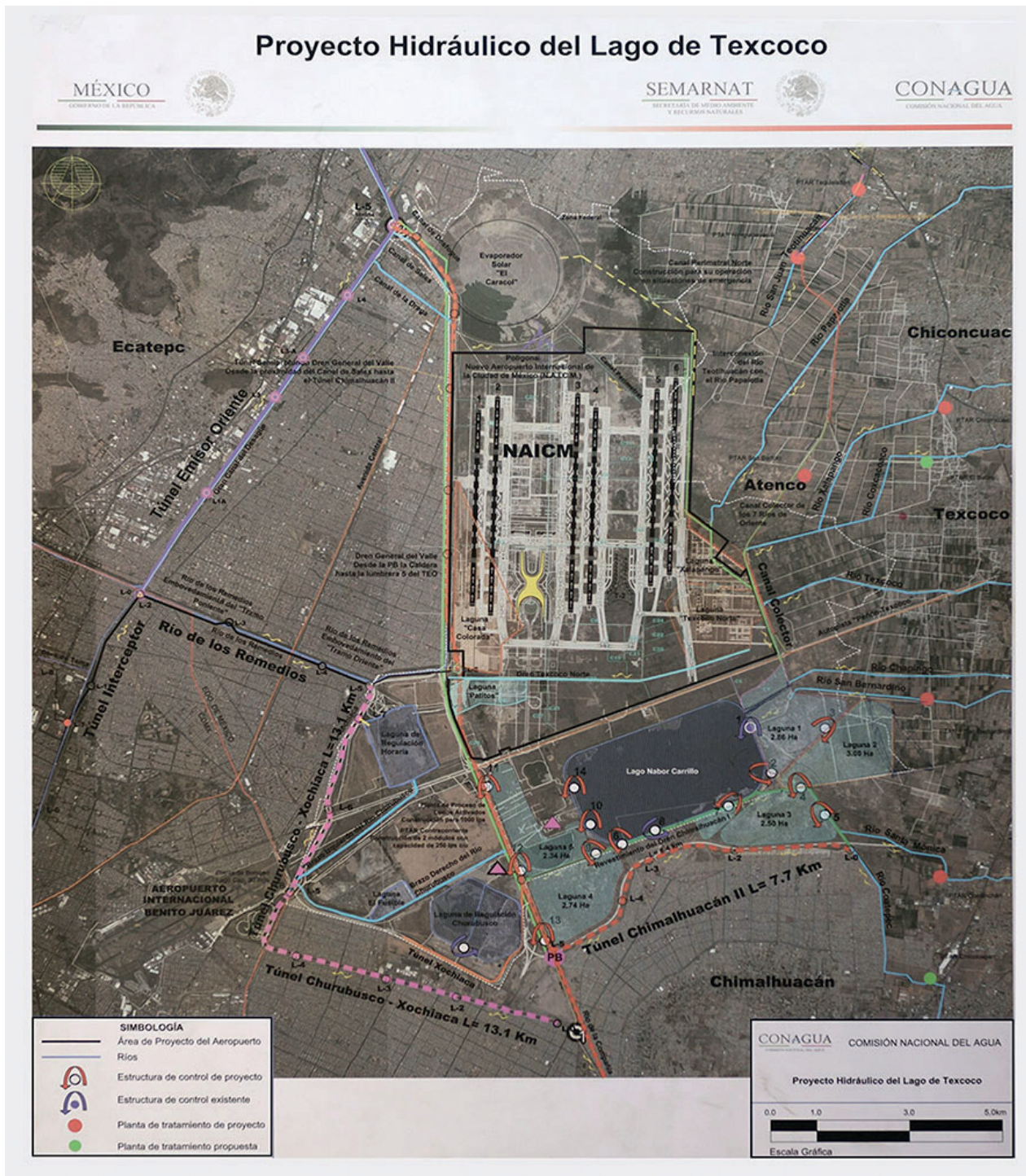

Figura 8. Proyecto Hidráulico del Lago de Texcoco, Conagua.

Mapa mostrado durante el recorrido por la Zona Federal del lago de Texcoco (8 de mayo de 2019). Fotografía de Alberto Naranjo 